\title{
PROCEEDINGS OF THE TWENTY-SIXTH ANNUAL MEETING OF THE AMERICAN SOCIETY FOR CLINICAL INVESTIGA- TION HELD IN ATLANTIC CITY, N. J., APRIL 30, 1934
}

\author{
Hyperparathyroidism Due to a Diffuse Hyperplasia of All Parathyroid Glands \\ Rather than to a Parathyroid Adenoma of One Gland-Clinical Studies \\ on Two Such Cases. By Fuller Albright, Edward D. Churchill, \\ and (by invitation) Benjamin Castleman, Boston, Mass.
}

After an experience with fourteen cases of hyperparathyroidism proven by operation, in which there was every reason to believe the hyperparathyroidism was due to an adenoma of just one of the glands, we encountered patients number 15 and 17 in our series in whom the situation was entirely different. Both of these individuals had typical hyperparathyroidism as judged by metabolic criteria. At operation all the parathyroid glands were found to be enormous, three being encountered in the first patient and four in the second. Removal of two glands in the first patient was without effect on the degree of hyperparathyroidism. Removal of three glands and part of the fourth produced the required effect in the second patient. It is apparent that the condition was a diffuse hyperplasia rather than an adenoma. The histology of the material removed was similar in both patients and differed markedly from that seen in our first fourteen cases. The analogy with Graves' disease is suggested. Certain difficulties in the treatment of such patients are presented. We believe this condition is a separate disease entity due to the presence of a parathyreotropic substance in abnormal amounts.

Observations on Adrenalectomized, Depancreatized Animals. By C. N. H. Long and (by invitation F. D. W. Lukens, Philadelphia, Pa.

In five cats we have removed, in stages, all the pancreas and both adrenal glands. Liberal dosage of a commercial cortical extract was immediately instituted but at no time was any insulin given. The periods of survival were $12,11,8$ and 6 days, while one animal was sacrificed in good health on the 7th day for determination of liver glycogen (2.5 grams per cent).

None of the animals presented the usual clinical picture of those depancreatized with the adrenals present. They remained active and ate fairly well up to the day of death. They have all died suddenly in convulsions.

The most striking features have been: $(a)$ the fasting blood sugars were, in the majority of observations, not above normal limits and showed a remarkable tendency after the first few days to fall to such low levels that convulsions, relieved by glucose, have occurred; $(b)$ glycosuria was slight or absent depending upon the amount and type of diet; $(c)$ metabolic balance sheets have been constructed and show that while considerable amounts of the glucose of the diet were utilized yet the tolerance was not normal.

These animals resembled those suffering from adrenal insufficiency in spite of the fact that supposedly adequate doses of cortical extract were administered.

A Study of the Acid-Base Equilibrium in a Patient with Acute Gout. Ву Јон

H. Talbott (by invitation) and Arlie V. Bock, Boston, Mass.

A 21-year old male patient suffering from recurrent attacks of gout has been studied on a metabolic regime for more than five months. Twelve complete 
cycles, comprising the attack and convalescence, have been investigated in detail. All of them have shown a similar phenomenon in respect to the acid-base changes of the blood and urine. One complete cycle of thirteen days will be reported at this time. This period started three days before the peak of the symptoms of one attack, continued through this attack and its recovery and extended through the prodromal period of the following attack.

On the metabolic regime the fluid and food intake was maintained constant. A low purine diet was given. Every fifth day a complete supply of food was purchased for the following days and a 50 per cent aliquot portion of a whole day's diet was analyzed. These analyses included $\mathrm{Na}, \mathrm{K}, \mathrm{Ca}$, total inorganic base, $\mathrm{P}, \mathrm{Cl}$, and total $\mathrm{N}$. Twenty-four hour urines were collected and analyzed for $\mathrm{Na}, \mathrm{K}, \mathrm{Ca}$, total inorganic base, $\mathrm{NH}_{3}, \mathrm{P}, \mathrm{Cl}$, urate, titratable acid and total N. The stools were collected in periods corresponding to phases of the attack and were analyzed for the same constituents as the diet. Daily venous blood samples were collected and equilibrated at $37.5^{\circ} \mathrm{C}$. at a known $\mathrm{pH}$. A portion of the whole blood was analyzed for uric acid and $\mathrm{CO}_{2}$. The remainder was centrifuged and the separated plasma was analyzed for $\mathrm{Na}, \mathrm{K}, \mathrm{Ca}$, total inorganic base, $\mathrm{CO}_{2}, \mathrm{P}, \mathrm{Cl}$, urate, non-protein nitrogen and total $\mathrm{N}$. The cells were analyzed for $\mathrm{Na}, \mathrm{K}, \mathrm{Cl}$ and $\mathrm{H}_{2} \mathrm{O}$.

One of the significant findings in this study was a diuresis preceding each attack, beginning at least twenty-four hours before any symptoms of acute gout. This diuresis continued after the onset of symptoms and reached a maximum on the third day. On this day, colchicine was administered to alleviate the pain. As the symptoms subsided the urinary output diminished and reached a minimum three days later. In convalescence, the urinary output gradually increased and reached a second maximum with the next attack, thus completing a cycle. The changes in the urinary volume were associated with an increased concentration of $\mathrm{Na}$ and $\mathrm{Cl}$ not noted in connection with any of the other electrolytes. On a daily intake of approximately $75 \mathrm{~m} . \mathrm{Eq}$. of $\mathrm{Na}$ and $\mathrm{Cl}$ the excretion of these substances was over $125 \mathrm{~m}$.Eq. on the day preceding symptoms. In the recovery phase there was a retention of the above to compensate for the dissipation. Other constituents of the urine which showed changes of excretion approximately proportional to the change in urine volume were $\mathrm{K}, \mathrm{Ca}, \mathrm{P}$ and uric acid. The excretion of $\mathrm{NH}_{3}$ and titratable acid showed no direct relation to the attacks. Approximate nitrogen balance was maintained through the cycle.

Regarding the constituents of the plasma, there was a gradual elevation of $\mathrm{K}$ from $3 \mathrm{~m} . \mathrm{Eq}$. to a peak of $6 \mathrm{~m}$.Eq. at the height of the attack. After the peak the $\mathrm{CO}_{2}$ increased $3 \mathrm{~m}$.Eq. and the $\mathrm{Cl}$ decreased $6 \mathrm{~m} . \mathrm{Eq}$. Cell volume and plasma protein concentration showed little change.

In summary, changes of considerable magnitude in the acid-base balance of the body have been observed in a patient suffering from acute gout, the interpretation of which is subject to further study.

Skin Temperature Changes Following Food Digestion. By George Booth and J. M. Strang (by invitation), and Frank A. Evans, Pittsburgh, Pa.

Variations of skin temperature following a meal of meat, designed to attain satiety, were made on twenty normal and thirteen obese patients. The Tycos dermatherm was used and each observation represents the average of two tc four determinations at four selected points.

Average of findings were: 


\begin{tabular}{l|c|c|c|c|c|c}
\hline \hline & \multirow{2}{*}{$\begin{array}{c}\text { Meat } \\
\text { eaten }\end{array}$} & $\begin{array}{c}\text { Duration of } \\
\text { eating }\end{array}$ & $\begin{array}{c}\text { Elevation } \\
\text { began } \\
\text { after }\end{array}$ & $\begin{array}{c}\text { Elevation } \\
\text { at time of } \\
\text { satiety }\end{array}$ & $\begin{array}{c}\text { Maximum } \\
\text { elevation } \\
\text { attained after }\end{array}$ & $\begin{array}{c}\text { Maximum } \\
\text { elevation }\end{array}$ \\
\cline { 3 - 7 } & grams & minutes & minutes & $\cdot C$. & minutes & $\circ C$. \\
Normal.. & 505 & 24 & 6 & 0.9 & 54 & 1.9 \\
Obese... & 495 & 25 & 25 & 0.1 & 45 & 0.6 \\
\hline
\end{tabular}

Only four of the twenty normal and five of the thirteen obese failed to show the characteristic pattern of curve.

Satiety, marked by a distinct sensation of warmth in most cases and by the appearance of gross perspiration in some, is probably related to the response of skin temperature to food. The depression and delay of this reaction, observed in the obese would permit of the ingestion of much larger quantities of food than would occur in persons of normal nutritional state.

A Peculiarity in Carbohydrate Metabolism of Cancer. By Frederick $\mathrm{H}$. Scharles, and Dwight Baker (by invitation), and William T. Salter, Boston, Mass.

High lactic acid production is known to be a common characteristic of intact malignant tissue. Nevertheless, no extract of malignant tissue has hitherto been found capable of producing lactic acid from glucose or glycogen. When a saline extract of mouse sarcoma No. 180 is incubated with a phosphatebuffered glycogen solution, the glycogen is hydrolyzed but no lactic acid is produced. Fresh muscle extract, on the other hand, incubated with a similar substrate, forms appreciable amounts of lactic acid. If, however, hexose diphosphate or hexose monophosphate (prepared from yeast) are used as substrate, tumor extract splits them with the production of lactic acid, just as does muscle extract.

This finding suggests that there is a deficiency in the enzyme system of extracted malignant tissue which has not hitherto been described. The reasons for postulating this deficiency are as follows: First, because it has been previously shown that a glycogen-splitting enzyme is present in sarcoma extract. Secondly, because Lohman's "coenzyme" (essential to lactic acid formation) is present in tumor as well as in muscle. Consequently, by elimination, the defect may lie in the inability of sarcoma extract to synthesize a precursor of lactic acid, possibly a hexose phosphate.

The State of Calcium in the Blood in Rickets. ${ }^{1}$ By Edward L. Compere (by invitation), FrankLIN C. McLean, and (by invitation) A. BaIRd HastINGS, Chicago, Ill.

Fifty-two observations were made upon the blood serum of twenty-one children diagnosed as with rickets. The children varied in age from five months to two and one-half years, and the diagnoses varied from very mild or doubtful to very active rickets. The study was begun before any treatment was instituted and extended into a period of about five weeks' treatment with cod liver oil or irradiated yeast; a control group remained untreated throughout.

1 This work has been aided by grants from the Josiah Macy, Jr., Foundation and the Quaker Oats Company. 
Total protein, inorganic phosphate, total calcium and calcium ion were determined simultaneously on each sample of blood (taken fasting), the first three by the conventional chemical methods. Calcium ion concentrations were observed directly by the frog-heart method (1), and calculated from the mass-law equation (2) previously described by two of the authors.

Total calcium, and calcium ion concentrations, both observed and calculated, were found to be in or very near the normal range throughout, and no correlation was found between the calcium findings and the severity of the rachitic process, as judged either by the inorganic phosphate concentration or by all clinical evidence available.

In the absence of the finding of any deviations from the normal or of any correlation with the severity of the rachitic process, it is concluded that the pathological state in rickets is apparently not to be explained upon the basis of any change in the state of calcium in the blood discoverable by this method.

1. McLean, F. C., and Hastings, A. B., Proc. Soc. Exper. Biol. and Med., 1933, 30, 1344.

2. McLean, F. C., and Hastings, A. B., Proc. Soc. Exper. Biol. and Med., 1934, $31,529$.

Observations on the Arginase Activity of Human Blood, with Particular Reference to Blood from Patients Suffering from Malignant Disease or Pernicious Anaemia. By James A. Dauphinée (introduced by Duncan Graham), Toronto, Canada.

A series of quantitative observations on the arginase content of human bloods has been made in normal individuals and in patients suffering from various types of disease. The enzyme has been found to be present in the red cells of all human bloods examined and to be practically absent from all samples of serum. It has been found that the red cells must be completely broken down with a haemolytic agent, such as' saponin, before their full arginase activity becomes apparent. No evidence has been found to support the contention that patients suffering from malignant disease show any increased arginase activity. As a general rule, patients who are cachectic, whether from malignant disease or other cause, tend to show lowered arginase values in the blood.

On the other hand, many patients who have severe or moderately severe pernicious anaemia show a marked increase in the arginase activity of the red cells. This may reach as high as ten times the normal value. With adequate liver therapy, this arginase activity of the red cells decreases rapidly at first and then more slowly approaches normal values. The high values found in the red cells of patients suffering from pernicious anaemia are not approached by those found in any other type of disease, including severe secondary anaemias and haemolytic icterus, so far examined.

No evidence has been obtained, therefore, that the arginase content of the blood is of any significance, diagnostic or otherwise, in patients thought to be suffering from malignant disease. The results obtained, however, with the bloods of patients suffering from pernicious anaemia are highly interesting. The reasons for the high arginase activity in the red cells of these patients is not at once apparent. Although an increased arginase content has been observed in the blood of most patients who have this disease with moderate to severe anaemia, yet there does not seem to be any direct relationship between the magnitude of this increase and the severity of the anaemia. In view of the fact that arginase has been shown by Edlbacher and others to be present in 
rapidly growing tumors, embryonal cells and young granulation tissue, we have considered the possibility of a relationship between the number of immature red cells in the circulation and the arginase content. Any such relationship, however, is discounted by the lack of parallelism between the arginase activity and the reticulocyte count, both in patients who have pernicious anaemia and in those having a reticulocyte response from other causes. It is probably more likely that the increase in arginase content is due to some abnormality other than immaturity of the red cells, which would seem to be peculiar to pernicious anaemia and which is abolished by treatment with liver. We are making this the subject of further study.

\section{Studies on the Mechanism of Hyperthyroidism. ${ }^{1}$ By DoNALD MCEACHERN} and E. Cowles Andrus, Baltimore, Md.

Using the Warburg-Barcroft technique, measurements were made of the respiration of representative tissues from normal and thyroxine-injected rats. At intervals of 22 hours to 8 days following a single injection of thyroxine (10 mgm. per kilo.) the following changes of tissue respiration were found in 11 experiments: Mean $Q_{02}{ }^{2}$ Kidney: Normal $=21.50$; Hyperthyroid $=27.62$ (+28 per cent). Liver: N. $=10.39 ; \mathrm{H}=12.88$ ( +24 per cent). Diaphragm: $\mathrm{N}=4.93 ; \mathrm{H}=5.12$ ( +4 per cent).

In 12 experiments following multiple injections of thyroxine (10 to $15 \mathrm{mgm}$. per kilo. from twice in 5 days to 8 times in 18 days) much greater increases of oxygen consumption were obtained, the mean $Q_{0_{2}}$ being Kidney: $\mathrm{N}=23.72$; $\mathrm{H}=34.65$ ( +46 per cent). Liver : $\mathrm{N}=9.59 ; \mathrm{H}=16.62$ ( +73 per cent). Diaphragm: $\mathrm{N}=4.71 ; \mathrm{H}=8.32$ ( +76 per cent). In all subsequent experiments hyperthyroidism was induced by multiple injections of thyroxine. In 13 experiments a comparison was made between the total metabolism of intact animals and the respiration and anaerobic glycolysis of their isolated tissues. A fair parallel was found in the oxygen consumption. The mean basal metabolic rate of hyperthyroid animals was +84 per cent and the increased $Q_{0_{2}}$ of their tissues was: kidney +61 per cent, liver +46 per cent, diaphragm +53 per cent. The anaerobic glycolysis was increased 90 per cent in kidney but in other tissues showed no significant change. In 15 experiments, methylene blue $(0.05$ per cent) caused similar changes in the respiration of normal and hyperthyroid tissues but the glycolysis of normal kidney and liver was accelerated three times more than in hyperthyroid tissues.

The respiration of hyperthyroid cells (in phosphate buffer) was more sensitive to cyanide than that of normal cells and with a concentration of $M / 2800$ $\mathrm{NaCN}$ the former was inhibited to a well sustained normal level. $\mathrm{KI}$ in concentrations of $1: 500,000$ and $1: 1,000,000$ had no significant effect on either normal or hyperthyroid tissues. Fluoride $(0.002$ to $0.0002 \mathrm{M})$ and iodoacetic acid $\left(10^{-5}\right.$ to $\left.10^{-6}\right)$ reduced the respiration of hyperthyroid cells to well sustained normal levels. Daily injections of fluoride and iodoacetic acid into hyperthyroid animals failed to prevent their decline and death. Muscle enzyme extract from normal and hyperthyroid animals when added to normal tissues caused approximately equal increases of respiration apparently due to the presence of metabolites. Hyperthyroid tissues were able to utilize sodium pyruvate, sodium d-lactate and sodium succinate (all $0.018 \mathrm{M}$ ) equally as well as normal

\footnotetext{
${ }^{1}$ From the National Institute for Medical Research, Hampstead, and the Cardiographic Laboratory, Johns Hopkins Hospital, Baltimore, Md.

${ }^{2} \mathrm{~mm}^{3}$ of $\mathrm{O}_{2}$ used per mgm. tissue (dry weight) per hour.
} 
tissues and responded by similar percentage increases of respiration of from 50 per cent to 150 per cent. Succinate caused the greatest increases. Dihydroxyacetone $(0.03 \mathrm{M})$ had no constant effect on the respiration of normal or hyperthyroid cells.

It was concluded that :

1. Representative tissues from hyperthyroid animals preserve an increased oxygen consumption after isolation from the animal body.

2. The increase in tissue respiration bears a fair parallel to the increase of total oxygen consumption by the intact hyperthyroid animal.

3. The increased moiety of respiration in hyperthyroid tissues is not carried out by any new or abnormal respiratory mechanism in the cell.

4. No increase in the inherent ability of the hyperthyroid organism to produce lactic acid can be demonstrated and an increased rate of glycolysis is not the fundamental cause of the increased oxygen consumption.

5. Cyanide, fluoride and moniodo-acetic acid reduce the excess respiration but do not affect the fundamental mechanism which makes an increased supply of oxygen necessary to the organism.

6. Hyperthyroid tissues are able to burn various substrates (lactate, pyruvate, succinate) as well as do normal tissues.

The Calorigenic Action of Various Thyroid Derivatives. By W. O. Thомpson and (by invitation) S. B. NAdLeR, S. G. TAYLOR III, and P. K. Thompson, Chicago, Ill.

We have found that, after peptic digestion of desiccated thyroid, about eighty per cent of its activity is possessed by the acid-insoluble portion, which contains less than half of the total iodine. The remaining activity is possessed by the acid-soluble portion, which contains the rest of the iodine. The curves denoting the change of the basal metabolism following single large doses of these two portions seem to be different. The activity of desiccated thyroid may not be proportional to its total iodine content, but only to a fraction of the iodine which possesses nearly all of the calorigenic activity. An iodine compound has been prepared from desiccated thyroid which, when given by mouth, possesses greater calorigenic activity per milligram of iodine than desiccated thyroid given orally and in some instances greater than thyroxine given intravenously.

Heating desiccated thyroid with alkali greatly reduces its activity, whereas this treatment does not affect the activity of thyroxine. Possible explanations are: 1. The active principle of the thyroid may be present in some form or forms other than thyroxine. 2. Thyroxine, when combined with other aminoacids in a protein molecule may be more susceptible to destruction than when present as the simple amino-acid.

The Standard Physiology of Extreme Old Age. By Howard F. Root and (by invitation) Francis G. Benedict, Boston, Mass.

The pathology and degeneration of old age are always before us. Observations upon a man 91 years of age disclose some of the physiologic phenomena of "ideal" old age. Mr. L. showed an extraordinary preservation of physical and mental power including libido normal for a man in youth. The basal metabolism showed an average oxygen consumption of $153 \mathrm{cc}$. per hour and respiratory quotient of 0.77 . The heat production of 18.3 calories per kilogram, or 629 calories per square meter is the lowest for all men examined at the Carnegie Nutrition Laboratory. It was 31 per cent lower than the average for 30 men of the same height and weight but younger in age. The depression of 
metabolism in extreme old age may not be properly expressed in the Aub-DuBois or Dreyer standards.

The low skin temperature of the feet $27.2^{\circ} \mathrm{C}$. in spite of good pulsation in the dorsalis pedis arteries suggests the factor of slow blood flow.

The insensible perspiration, blood chemistry, urine chemistry, hematology and roentgenograms demonstrating absence of calcification in the arteries are reported.

Changes in the Minute Volume Output of the Heart and Urea Clearance in Relation to Age. By William H. Lewis, Jr., and Alf S. Alving (introduced by Oswald T. Avery), New York, N. Y.

Twenty normal active men in each decade of age from the 5 th to the 10th have been studied. The observations to be reported included measurements of the minute volume output of the heart, the function of the kidneys illustrated by urea clearance, curves of the consumption of oxygen, vital capacity of the lungs, action of the heart manifested electrocardiographically, and data concerning the size and shape of the heart and the thoracic aorta as seen in $\mathrm{x}$-ray photographs.

The curves show that the behavior of the human organism alters significantly after the 65th year. The basal consumption of oxygen, the vital capacity, and the renal function decrease; their decline presents a parabola like curve. The minute volume output of the heart under basal conditions and corrected to body size remains at the level for adults between the ages of 20 and 40 years.

The study considers aspects of physiological evolution by simultaneous analysis of the functions mentioned over a given period of life.

Quantitative Tissue Reactions in Normal and Immunized Rabbits Following. the Intravenous Injection of Non-Pathogenic and Pathogenic Bacteria. By Robert N. Nye, Boston, Mass.

The rate of disappearance of intravenously injected $B$. subtilis from the blood stream, the localization of the bacteria in the lungs, liver, spleen and bone marrow and the changes in the distribution of the polymorphonuclear leukocytes in the blood, lungs, liver, spleen and bone marrow, all in normal rabbits, serve as a basis for comparison.

The rapid disappearance of polymorphonuclear leukocytes from the blood stream appears to be directly proportional to the rate of removal of bacteria from the circulation in all experiments; intravascular phagocytosis, however, is extremely rare. The removal of the spleen does not affect the rapid clearing of the blood stream of bacteria, nor does superimposed blocking of the hepatic circulation. Staphylococci are removed about as rapidly as hay bacilli, but dead and live pneumococci either persist for longer periods or actually increase. Both dead and living pneumococci, however, disappear in immunized animals with a rapidity nearly comparable to that of other bacteria, although immunization has no affect upon the removal rate with $B$. subtilis.

The localization of polymorphonuclear leukocytes in any organ appears to be directly proportional to the number of bacteria found in that organ. Whereas phagocytosis by these leukocytes, primarily in the lungs and liver, is relatively common following the injection of hay bacilli and staphylococci, it is seen only rarely with pneumococci. The latter are phagocytized chiefly by cells of the reticulo-endothelial system in the liver and spleen; but this process is accompanied by the localization of polymorphonuclear leukocytes. 


\section{The Influence of Lipoids in Tissue Immune Reactions. By FRAN KLIN M.} HANGER. New York, N. Y.

Immune responses are traditionally measured by serological changes. However, it is well recognized that some of these responses are demonstrable only by an altered tissue reactivity. The influence of lipoids on the serological changes of immunized animals has been frequently studied, but their effect on tissue reactivity has not been adequately investigated.

A group of rabbits has been vaccinated intradermally with living and heatkilled strains of hemolytic streptococcus. Another group of animals received identical doses of vaccine to which various lipoids were added. The chief effects noted were:

1. The sites of intradermal vaccination healed more promptly with lipoids present.

2. Allergic response as expressed by skin tests with bacterial proteins seemed diminished in the lipoid treated animals.

3. Animals injected with streptococcus alone showed no immunity when subsequently infected with a virulent strain of $B$. lepisepticum. However, many animals treated with the streptococcus lipoid mixture showed immunity, though no demonstrable protective antibodies developed in their sera.

4. Purified lipoids failed to produce the effects noted above.

5. If rancid lipoids were injected with the vaccine a reversed influence was observed and the resistance of the animal was markedly diminished.

6 . Intravenous injections of lipoids had no demonstrable effect on vaccination.

Cutaneous Reactions in Pneumonia to the Somatic ("C") Polysaccharide of Pneumococcus. By Thomas Francis, JR. and (by invitation) T. J. Abernethy, New York, N. Y.

The capsular polysaccharide of pneumococcus is type-specific; its intradermal injection elicits an immediate wheal and erythema reaction in the skin of patients with pneumonia at the onset of recovery. The reaction is type-specific and occurs only in the presence of homologous type-specific antibodies.

The somatic carbohydrate, or "C" fraction, is not type-specific. It is derived from pneumococci of all types or even from degraded unencapsulated forms. During the acute phase of pneumonia, precipitins to the somatic carbohydrate are demonstrable in the serum of pneumonia patients, but disappear with recovery. Similarly, skin reactions to the somatic carbohydrate are elicited during the febrile stage of pneumonia and become negative in convalescence.

The cutaneous response first appears as an immediate wheal and erythema, which is followed by the delayed reaction, an edematous erythema. The center of the delayed reaction is frequently dark, reddish brown, sometimes hemorrhagic; about this there may be a pale white halo; and beyond this a bright red erythema. The delayed reaction begins to appear in 2 to 3 hours, is well marked in 6 to 10 hours, persists for about 18 hours, and then fades leaving a residual brown stain. The reaction may vary from 1 to $5 \mathrm{~cm}$. in diameter.

In general, the reaction is related to the presence of precipitins in the serum, and is apparently a true antigen-antibody reaction. It may have a prognostic significance, in that cases which terminate fatally fail to give a positive skin test. The reaction is not specific, since it may also be elicited in certain other acute infections, such as rheumatic fever, but not in all febrile states. Normal human subjects usually give no response. 
Reappearance of Clinical Signs and Symptoms of Rheumatic Fever Following Non-specific Protein Shock. By T. DucketT Jones and (by invitation)

EDWARd F. BLAND, Boston, Mass.

Upper respiratory infections frequently precede the onset of clinical recurrences of rheumatic fever by from several days to three or four weeks. However, seemingly unrelated episodes such as tonsillectomy, abdominal operations, accidents and unexplained fever have also been noted. Since protein shock by means of intravenous administration of typhoid-paratyphoid vaccine has been widely used as a therapeutic measure in many diseases, it was thought justifiable to use this means to reproduce the fever (commonly associated with respiratory infection, but occasionally unexplained) which is often observed before the onset of clinical rheumatic fever.

Twelve observations were made upon ten hospitalized patients convalescing from recent rheumatic fever, in whom the clinical symptoms and signs of the disease had subsided, but in whom in most instances there remained laboratory evidence of low grade persistent infection. Non-specific protein shock was induced by the intravenous administration of $0.1 \mathrm{cc}$. of a stock typhoid-paratyphoid vaccine with resulting chill and rectal temperature of approximately $103^{\circ} \mathrm{F}$. In six instances (50 per cent) a recurrence of clinically active rheumatic fever appeared either immediately or after a latent period of one to three weeks. Artificial fever, induced by radiant heat in three of the same group, was not followed by similar recurrences. It is evident that the signs and symptoms of clinical rheumatic fever (recurrent) may follow the use of non-specific protein shock.

Scarlet Fever and Rheumatic Fever. By JoHn R. PAUL, New Haven, Conn.

Recent emphasis upon the rôle of Streptococcus hemolyticus infections as a contributing or "activating" cause of rheumatic fever, has made it worth while to analyze certain late complications of streptococcus infections and to compare them to rheumatic fever. Scarlet fever is one of the streptococcus infections often followed by complications, such as arthritis and heart disease which resemble the arthritis and carditis of rheumatic fever. How close this resemblance is has for years been an unsettled question.

Three points of similarity are shown:

(a) The clinical course of scarlatinal nonsuppurative sequelae resembles that of rheumatic fever following an upper respiratory infection, and the interval at which arthritis, carditis and nephritis arise following scarlet fever simulates the interval at which rheumatic fever occurs after tonsillitis.

(b) From the standpoint of familial epidemiology it is shown that a high incidence of rheumatic fever exists in the families of patients who sustain arthritis and carditis after scarlet fever.

(c) A fatal case of post-scarlatinal myocarditis is reported in which Aschoff bodies were found, together with other histological lesions identical with those of rheumatic heart disease.

The significance of this resemblance which these scarlatinal sequelae bear to rheumatic fever is discussed in the light of the pathogenesis of the latter disease. 
The Significance of the Relief of Pain Immediately after Complete Removal of the Normal Thyroid Gland in Patients with Angina Pectoris and Congestive Heart Failure. By H. L. Blumgart and (by invitation) A. A. Weinstein, D. Davis and J. E. F. Riseman, Boston, Mass.

In treating over sixty patients with angina pectoris and congestive heart failure by removing the entire normal thyroid gland, we have observed that the most striking clinical improvement occurs when the hypothyroid state develops, as gaged by the lowering in the basal metabolic rate. Immediately after operation it has been noted, however, that, at a time before the basal metabolic rate has become significantly lowered or the velocity of blood flow has become slowed, patients very frequently lose localized areas of thoracic tenderness and of constant precordial pain and frequently no longer suffer from attacks of angina pectoris. Extensive studies of this phenomenon have been made for over a year both in patients after bilateral complete thyroidectomy and in patients who have had only one lobe of the thyroid removed at the time of the first operation. These studies will be described.

The observations point definitely to the following conclusions: (1) the immediate relief of pain after total thyroidectomy is due to the interruption of nerve impulses from the heart at the time of operation; (2) relief of pain by this mechanism is only temporary; (3) permanent relief is related to the lessened work of the heart attendant on the development of the hypothyroid state. These findings' indicate that after total ablation of the thyroid, complete bed rest should be enforced, despite the early subjective relief experienced by the patient, until the basal metabolic rate shows significant lowering.

The Effect of Theophyllin Ethylendiamin on Experimentally Induced Cardiac Infarction in the Dog. By W. M. Fowler and H. M. Hurevitz (by invitation) and FRED M. SMITH, Iowa City, Iowa.

In perfusion experiments on the isolated heart of the rabbit theophyllin ethylendiamin produced a far greater and more consistent increase in the rate of coronary flow than did any of the other drugs tested. This drug was put to a more decisive test by observing its effect on the infarct produced by the ligation of a coronary artery in the dog. Observations were made during the initial stage of the infarction and after an interval of three weeks. In the first series of experiments a coronary vessel was ligated and, after the appearance of the distal area of cyanosis, the drug was administered intravenously. This was followed by a decided reduction in the extent and degree of the cyanosis and, in certain instances, resulted in almost complete restoration of the original color. The drug was then given at daily intervals to a series of animals after the ligation of a coronary artery. These animals were sacrificed after an interval of three weeks, which, in view of the findings, allowed ample time for the maximum restoration of the circulation to the area of infarction. This area was greatly diminished in these animals as compared to that in the control series which did not receive medication and in which a corresponding vessel was ligated at the same level. These results indicate that theophyllin ethylendiamin promotes the development of an extensive collateral circulation.

Cardiac Pain. The Presence of "Pain" Fibers in the Nerve Plexus Surrounding the Coronary Arteries. By L. N. KATZ and (by invitation) W. Mayne and W. Weinstein, Chicago, Ill.

Sutton and Lueth observed symptoms resembling an "anginal attack" in unanesthetized dogs when a large coronary artery was occluded; an observation 
which has been confirmed by Piercy, Priest and Van Allen, and by J. C. White. Sutton and Lueth concluded that the response was precipitated by myocardial ischemia.

Some recent results led us to conclude that this response was due to direct stimulation of the "pain" fibers in the nerve plexus which Woollard found encircles the coronary vessels. Our evidence for this is :

1. Occlusion of a carefully isolated coronary artery gave no "anginal" response. However, a definite response was obtained when the compression was applied to the undissected coronary vessels above and below this point.

2. The destruction of the nerve plexus with phenol-alcohol changed a positive to a negative response without affecting the positive response produced by compression of the vessel above the phenolized area.

3. Complete preliminary occlusion of a carefully isolated coronary artery did not prevent a positive response to compression of the vessel above and below this point.

4. Pericardial tamponade, following bleeding from a ruptured coronary artery, caused syncope but no "anginal" response.

The response from the heart was similar to that obtained on compressing a superficial somatic sensory nerve, save for an inability to locate the site of irritation.

The Contour of the Chest as a Factor in the Explanation of the Difference Between the Dog and Human Electrocardiogram. By M. Prinzmetal (by invitation), W. B. Kountz and D. P. BARR, St. Louis, Mo.

Recent studies by us on revived perfused human hearts have verified the results obtained by Barker, McCloud and Alexander on the electrocardiogram in man. The explanation of the difference obtained by Barker and Lewis was thus sought.

When the chest plate was removed in the cadaver it was noted that there was no displacement of the human heart, whereas when the dog's chest was opened the heart was displaced posteriorly. Experiments were designed to study the dog's heart in the anterior mediastinum, and it was found that the electrocardiographic tracings resembled more closely those obtained by Barker in man than those obtained by Lewis in the dog.

The following experiment was performed to study the problem further. The human heart was removed from a cadaver. Dog's heart-lung preparations were made and the beating dog's heart was inserted into the human pericardial cavity. The leads were taken from the cadaver's extremities. Extrasystoles and bundle-branch-blocks were identical to those found in the exposed human hearts.

Since the dog's heart in the human chest and in its normal position in the dog's chest is electrocardiographically similar to the human heart, anatomical differences between the hearts of the two species cannot be used as an explanation for the electrocardiographic differences. The explanation, therefore, must lie in the difference in contour of the chest of the two species.

\footnotetext{
Observations on Arterial Function. By RoY H. TURNER and (by invitation) William A. Sodeman, New Orleans, La.

In a study of pulse-wave velocity in which 100 determinations were made in twenty-two normal adults and 82 determinations in thirty-one individuals with hypertension or arteriosclerosis or both, certain observations were made which are not in accord with widely accepted concepts of arterial function:
} 
1. Pulse-wave velocity in normals as a group and repeated determinations in the same group of individuals varied widely, including high values such as: 12.2, 12.0, 11.6, 11.3, 10.8, $10.7 \mathrm{~m}$. per sec.

2. Pulse-wave velocity in some patients with hypertension or arteriosclerosis or both were as low as: 4.1, 4.2, 4.3, 5.7, 4.8, 4.9, 4.4, 5.1, $6.1 \mathrm{~m}$. per sec.

3. Fall in blood pressure was frequently associated with a rise in pulsewave velocity.

4. In our normal group pulse-wave velocity tended to fall as pulse rate rose.

Explanation of high pulse-wave velocity in normal arteries with normal blood pressure and of low pulse-wave velocity in thickened arteries, with or without high blood pressure, depends upon changes of tone of smooth muscle in the arterial walls or changes in diameter of arterial lumen or both.

These findings indicate that until conditions have been defined which insure maximum elasticity of which the artery is structurally capable, determinations of pulse-wave velocity will be of little aid in detecting the presence of arteriosclerosis and measuring its degree.

The Cerebral Circulation. XXXII. The Effect of Sympathetic Nerve Stimulation on the Pial Vessels in the Isolated Head. By J. L. Pool (by invitation) and H. S. Forbes, Boston, Mass.

It has been shown that stimulation of the cervical sympathetic nerve is usually followed by constriction of the ipsolateral arteries of the pia mater, and presumably of the ipsolateral cerebral arteries in addition. Similar results have been attained in experiments on a partially isolated head mechanically perfused by the animal's own blood. In all this work, however, the possibility of an hormonal effect existed, indicating the necessity of an experiment in which a closer approach to physiological conditions prevailed, and which, at the same time, would eliminate all effects other than the direct action of sympathetic nerve stimulation on the intracranial vessels.

Therefore, microscopic measurements of the pial vessels were made in a head completely isolated from its body, circulation being maintained by direct vascular anastomosis with a living intact animal serving as donor.

Sympathetic stimulation in five such preparations resulted in an average constriction of the ipsolateral pial arteries amounting to 9.6 per cent, 19 times out of 21 trials. No change occurred in the remaining 2 trials. No effect on the contralateral vessels was noted. A concomitant decrease in the cerebrospinal fluid pressure of the isolated head amounting to 14 per cent also occurred.

The Etiology of "Alcoholic" Polyneuritis. By Maurice B. Strauss (introduced by Henry Jackson, Jr.), Boston, Mass.

The clinical and pathologic similarity of alcoholic polyneuritis and beri-beri has recently been pointed out. Minot, Strauss, and Cobb have shown that patients with alcoholic polyneuritis usually have had a poor diet and have eaten relatively little food over long periods of time. Frequently gastro-intestinal disturbances occur, possibly due to the effects of excessive alcohol, which may interfere with the absorption of accessory food factors. Fifty per cent of our 43 patients had gastric anacidity, and 25 per cent had pellagra in addition to polyneuritis, which favors the view that dietary deficiency plays a rôle in the latter condition. Spies and De Wolf have shown that "alcoholic" pellagra may be cured during the continuous administration of alcohol by the use of a diet rich in vitamin $B_{2}$. This suggested that "alcoholic" polyneuritis might be relieved during the continuous administration of alcohol by a diet rich in 
vitamin $B_{1}$. Accordingly, seven patients suffering from alcoholic polyneuritis, in one instance complicated by an alcoholic psychosis, have been given a diet rich in the vitamin $\mathrm{B}$ complex together with intramuscular injections of vitamin B concentrates. In each instance the patient was furnished with his usual daily allowance of alcoholic beverage, this varying from one pint to one quart of 100-proof spirit. Without exception the patients showed steady improvement under this regime. Pain disappeared. Motor power and sensation returned. Absent reflexes reappeared in one case during the period of observation. The patient with least disturbance was well within two weeks, whereas the most severely paralyzed individual required four months of treatment. These observations constitute definite evidence that pure alcohol does not have a specific neurotoxic effect on the peripheral nervous system. Although the possibility remains that some impurity in the beverage alcohol consumed by these patients before the onset of polyneuritis was responsible for the nerve lesions, all the evidence thus far presented suggests that alcoholic polyneuritis is a dietary deficiency disease similar to beri-beri.

The Abortion of Migraine Headaches by Means of Ergotamine Tartrate. By William G. Lennox, Boston, Mass.

Forty-five patients suffering from migraine have been given ergotamine tartrate (Gynergen) during a headache. All of these patients were chronic cases with frequent headaches which were not relieved by the drugs commonly used. Injection of the ergotamine tartrate was followed by abrupt termination of the headache in question in 40 of the 45 patients, i.e., 90 per cent. In all but a few cases the medicine was given intravenously $(0.25$ to $0.5 \mathrm{mgm}$.). Relief was somewhat less sure if the subcutaneous route was used. Oral administration ( 1 to $2 \mathrm{mgm}$.) was of value only in mild attacks. Relief required about $\mathbf{3 0}$ minutes by the intravenous, 60 minutes by the subcutaneous, and two to three hours by the oral route. Eight of the patients have used ergotamine tartrate with repeated attacks for a period of from 6 to 18 months. In one of these, the effectiveness of the drug has been lost and its use discontinued. In the other seven patients, individual attacks are uniformly relieved. The attacks are less frequent in two patients, more frequent in three, and have not changed in two.

Ergotamine is not ordinarily effective in headaches which are not migrainous in character. Investigations are being conducted in an effort to explain the mechanism by which ergotamine tartrate so often produces such dramatic relief.

The Circulatory Response to Exercise in Patients with Angina Pectoris. Therapeutic Implications. By S. H. Proger and (by invitation) W. R. MINNICH, Boston, Mass.

The circulatory response to exercise has been studied in 16 patients with angina pectoris and 6 normal controls in the same age group. A stationary bicycle at a fixed load and speed was used. Blood pressure, pulse rate, respiratory rate, pulmonary ventilation and oxygen consumption were recorded before, during and after exercise.

There were four general types of response, the most significant disturbance in these groups being: (1) failure of pulse rate to rise normally during exercise; (2) primary respiratory distress with rapid pulse rate; (3) the development of extrasystoles shortly before the onset of pain and disappearance shortly after cessation of exercise; (4) a rapid, barely palpable pulse during exercise which becomes strong after cessation of exercise. In only one patient could the response be termed normal. 
Groups 1, 2 and 3 suggest definite corrective therapeutic procedures, which have been studied. Quinidin was strikingly effective in Groups 1 and 3.

The effects of thyroidectomy, cold temperature, a large meal and nitroglycerin were also studied.

Arteriography. By EdgaR V. Allen and (by invitation) John D. CAMP, Rochester, Minn.

The arteries of the upper extremity of 75 living subjects were visualized roentgenographically following intra-arterial injection of a radiopaque medium. Local anesthesia was used and incision of the skin was unnecessary.

Three stages of involvement of arteries were seen in thrombo-angiitis obliterans: the primary stage was shown as simple changes in the contour of the artery; the secondary stage appeared as extensive encroachment on the arterial lumen which was represented by irregular channels; the tertiary stage was indicated by complete occlusion of the artery. "Patchy" involvement was characteristic; an artery might be extensively involved, while those in the immediate neighborhood appeared normal and all stages of involvement could be seen in the same arteriogram. The collateral circulation was impressive and appeared able to nourish the tissues of an extremity adequately when the main arteries were completely occluded. Arteries extensively sclerosed had an irregular, moth-eaten appearance and the lumens were reduced in caliber. An aneurysm of the popliteal artery showed clearly as a saccular dilatation surrounded by a mass of soft tissue representing mural thrombosis. Arteriovenous fistulas were characterized by enlargement of the arteries leading to the fistulas, "pooling" of the radiopaque medium in the region of the fistulas and incomplete filling of the arteries distal to the fistulas. The digital arteries of patients with scleroderma were frequently observed to be fine and twig-like; circulation to the digits was definitely impaired. Interpretation of the findings in scleroderma must await more extensive pathologic observations.

The Demonstration of a Parathyreotropic Substance in Increased Amounts in the Urine of Patients with Hyperparathyroidism Due to Diffuse Hyperplasia of All Parathyroid Glands. By SAUL HERTZ (introduced by Fuller Albright), Boston, Mass.

We have demonstrated elsewhere that anterior pituitary extracts contain a substance which regularly produces parathyroid hyperplasia in a rabbit. It was, therefore, of interest to see whether a parathyreotropic substance could be found in the urine of the two patients with clinical hyperparathyroidism in whom hyperplasia of the parathyroid glands rather than adenoma was found. This we have succeeded in doing. The gross and histological findings in the parathyroid glands of the injected rabbits are presented.

This finding establishes, we believe, on a firm foundation the existence of a disease entity due to the overproduction of a parathyreotropic substance. That this substance in these cases originates in the pituitary is an attractive but as yet unproven hypothesis.

The Phosphatase Content of Blood Plasma and Tumor Tissue in Malignant Diseases of Bone. By Clifford C. Franseen (by invitation) and JoSEPH C. AUB, Boston, Mass.

Determinations of the phosphatase content of blood plasma by Kay's method, show a distinct elevation in patients bearing an osteogenic sarcoma. After removal of the osteogenic lesion, as by amputation, the level of the plasma 
phosphatase rapidly returns to normal; but with recurrence of the tumor, whether locally or as metastases, the plasma level again rises. The phosphatase content of osteogenic tissue exceeds that of any other tissue examined. Correlation of the phosphatase content of various portions of these tumors with the microscopic findings suggests that the enzyme is the product of the osteoblast, or of its immediate precursor, since it is present in large quantities even before osteoid tissue is produced and while the primitive osteoblast still resembles the fibroblast. Elevation of the level of blood plasma phosphatase may reveal early metastases or recurrences in patients who have had primary osteogenic sarcomata removed. Investigations indicate that the determination of the phosphatase level of the blood and the phosphatase content of the tumor tissue removed at operation may be of clinical value in the differential diagnosis of bone tumors.

Factors Determining the Effect of Exercise on Blood Sugar in the Diabetic.

By Russell Richardson, (introduced by J. H. Austin) Philadelphia, Pa.

Sixty diabetic patients, without food or insulin for 16 hours, were given a standardized form of exercise on a rowing machine, blood sugars being taken at the beginning and at the end of the half-hour period of exercise. The blood sugar decreased during exercise in patients whose fasting blood sugar was below 175, remained constant in those with a fasting blood sugar between 175 and 300 and usually increased in those patients with a fasting blood sugar above 300.

On eight from the last group the experiment was repeated but with 0.1 unit of insulin intravenously; seven of these then showed a decreased blood sugar during the exercise.

Two patients with severe diabetes were given repeated exercise with different combinations of insulin and food. It was found that exercise after insulin or food is accompanied by a fall in blood sugar in patients in whom the same exercise, during the fasting state, results in an unchanged or increased blood sugar.

The results after insulin with rest and with exercise, and after rest or exercise without insulin were investigated in a group of 10 diabetic patients of various degrees of severity. These experiments showed that 0.5 unit of insulin given intravenously was apparently used up during the succeeding half hour of rest and was not available during the immediately following half-hour period of exercise.

The effect of exercise in the diabetic depends upon the initial level of blood sugar and is influenced by even very small amounts of effective insulin.

\section{Cost of Work in Patients with Hypermetabolism Due to Leukemia and to} Graves' Disease. By Stella Paisley Briard and J. T. McClintock (by invitation) and C. W. BALDRIDge, Iowa City, Iowa.

The metabolic rate in the standing position and the cost of horizontal walking in gram calories per kilogram meter were measured in 12 patients with leukemia and in 8 patients with Graves' disease.

In the patients with leukemia the basal metabolic rate varied from 4 to 78 per cent above normal (average 35 per cent). The cost of walking varied from 14.7 per cent above normal to 34.4 per cent below normal (average of 28 tests : - 5.8 per cent). The average standing metabolism was 15.4 per cent above the basal metabolic rate (normal about 12 per cent). Of the energy required for walking, 27.5 per cent was used to lift the body. 
In the patients with Graves' disease the basal metabolic rate varied from 7 to 72 per cent above normal (average 40 per cent). The cost of walking varied from 4.6 to 73.1 per cent above normal (average of 20 tests : +38.5 per cent). The average standing metabolism was 25.1 per cent above the basal metabolic rate. Only 15.5 per cent of the energy used in walking was used to lift the body. One patient with myxedema (basal metabolic rate: -42 per cent) used 18.6 per cent less energy than normal in walking. The standing metabolism was used as the base from which to calculate the cost of walking.

Abdominal Disease Simulating Coronary Occlusion. By PAUL S. BARKer, Frank N. Wilson and (by invitation) Frederick A. Coller, Ann Arbor, Mich.

In recent years much emphasis has been given to the fact that acute coronary occlusion may resemble acute surgical conditions of the upper abdomen. The fact that disease of the upper abdomen may simulate coronary occlusion has been frequently overlooked. Owing to this, and to the widespread interest in coronary occlusion, cases of upper abdominal disease are now encountered in which the erroneous diagnosis of coronary occlusion or angina pectoris has been made. Unless the symptoms and signs are unequivocal, the diagnosis of angina pectoris or coronary occlusion should not be made until upper abdominal disease has been excluded. Five illustrative cases are presented. In the first three the symptoms were caused by gallbladder disease, but erroneous diagnoses of coronary disease had been made. The fourth was a case in which perforation of a gastric ulcer was accompanied by many of the manifestations of acute coronary occlusion, and only rather complete studies revealed the true condition. In the fifth case both cholelithiasis and angina pectoris were present. Coronary occlusion occurred a few days after cholecystectomy. Following his recovery the patient had no cardiac or abdominal symptoms.

Intra-articular Changes Resulting from Displacement of the Patella. By Granville A. Bennett (by invitation) and Walter Bauer, Boston, Mass.

Information concerning the effects of unusual and continued trauma to joint structures is desirable for a better understanding of the factors involved in the production of hypertrophic or degenerative arthritis.

In an earlier investigation concerning the repair of articular cartilage in the knee joints of dogs, the patellae in a number of joints became permanently displaced. Such displacement was toward the medial side of the joint so that the patella was in apposition with the medial epicondylar ridge of the femur. This antatomical derangement was invariably followed by marked intraarticular changes similar to those of hypertrophic or degenerative arthritis in man. Because of these observations further studies concerning the effects of patellar displacement were undertaken. Such experiments were carried out on rabbits where the desired derangement can be produced without opening the joint space or otherwise injuring any of the joint structures. Gross and microscopic examination of these joints revealed that anatomical changes, similar to those of hypertrophic arthritis, occurred as early as four weeks. These changes progressed and became more marked in the experiments of longer duration. Marked lipping of the articular margins of the femur occurred. This was accompanied by degeneration of original articular cartilage surfaces and in some instances by eburnation of the denuded subchondral bone.

Evidence has also been obtained that hypertrophic or degenerative arthritis develops at an early age in human subjects with displaced patellae and that in 
older individuals this anatomical derangement is apparently a cause of unusually extensive changes.

These experimental and clinical findings serve to emphasize the importance of continued trauma, unusual use, and wear and tear in the production of the intra-articular changes which have been designated as hypertrophic or degenerative arthritis.

The Effect of Elevated Metabolism on the Heart Weight of Frizzle Fowl. By ERNST P. Boas and (by invitation) Walter Landauer, New York, N. $Y$.

Frizzle fowl, owing to its scanty plumage, exhibits a profound disturbance of heat regulation with a resulting high basal metabolism in the absence of hyperthyroidism. We have shown that frizzle hens have heart rates 27 per cent, and frizzle roosters 68 per cent above that of normal chickens. We have weighed the hearts of 110 chickens by a modification of Müller's method. Of these 37 were normal females, 33 frizzle females, 20 normal males, and 20 frizzle males. In proportion to body weight the total ventricular weight of frizzle chickens is significantly greater than that of normal chickens. In frizzle pullets the difference is 0.7 with an error of \pm 0.14 . The ratios between right and left ventricles, whether or not the septum be included, are practically the same for frizzle as for normal fowl, so that both ventricles share equally in the hypertrophy that takes place. It would appear that hypertrophy, as well as tachycardia, are conditioned only by the high metabolism of the frizzle fowl. The fact that an increased metabolism alone may cause cardiac hypertrophy and tachycardia suggests that in Graves' disease the elevated metabolism per se increases the work of the heart, and in this manner directly contributes to the cardiac disturbances that are so commonly observed.

The Heredity Factor in Obesity: A Preliminary Report. By RAMSDELL GuRNEY (introduced by Byron D. Bowen), Buffalo, N. Y.

Eighty-one per cent of 50 obese women questioned, were found to have one or both parents obese, as compared to 47 per cent of 50 non-obese women taken at random. The two groups were approximately from the same age periods. They had also approximately the same incidence of operations and pregnancies, these two being the most common factors associated with the onset of obesity13 and 46 per cent respectively.

The builds of the offspring of the different matings were also studied with results similar to those found by Davenport in his report in 1923. Difference in variability of the progeny of different matings was present with the offspring of two slender parents least variable and the offspring of the stout and slender matings most variable. These findings strongly support the presence of segregation which in turn is evidence for Mendelian inheritance. Obesity was only slightly dominant over slenderness.

Transmission of Encephalitis to Mice from Human Brain Material preserved three months in Glycerin and Comparison of this Virus with the Virus of an Epidemic of Tracheobronchitis and Pox present in Foul in the St? Louis Area simultaneously with the Encephalitis Epidemic. By G. O. Broun and (by invitation) R. O. Muether and W. D. Collier, St. Louis, Mo.

Brain material of two of seven cases of epidemic encephalitis preserved approximately three months in glycerin, yielded a virus pathogenic for white 
mice and apparently identical with a strain of encephalitic virus secured through the courtesy of Dr. Muckenfuss.

Approximately, 75 per cent of the early cases in the St. Louis encephalitis had some contact with chickens. Moreover, tracheobronchitis and fowl pox was at that time present in epidemic proportions in many St. Louis county flocks including 20 flocks in close proximity to cases of encephalitis.

Chickens inoculated during the epidemic with fresh whole blood and brain material of encephalitic cases developed tracheobronchitis and pox. Spontaneous infection, however, can not be ruled out in these experiments.

The more recently isolated mouse virus has been compared with the virus of this epidemic disease of fowl.

While a mild, avirulent type of encephalitis has been produced in mice with material from chickens ill with pox and tracheobronchitis (acquired spontaneously or subsequent to inoculation with human brain material), nevertheless, the evidence at present available indicates rather distinct differences between the two viruses.

\section{A Quantitative Study of Fat Absorption in Gallbladder Disease: Non-visualiza- tion of the Gallbladder and the Ability to Absorb Fat. By Charles L. Brown and (by invitation) John D. Cameron, Ann Arbor, Mich.}

This reports an investigation of the ability of patients with chronic cholecystic disease, without common bile duct obstruction, showing non-visualization of the gallbladder, to absorb fat.

Weighed mixed diets were given in two periods of three days each: the first, a control period, using 40 grams of fat daily; the second, a test period, using from 150 to 200 grams of fat daily. The diets for the two periods differed only in that additional fat, as butter, was given in the test period. The total feces for each dietary period was obtained, using charcoal and carmine as markers. Quantitative fat determinations on the feces were made by Saxon's method. Fractionation of the fat is in progress. Protein absorption was determined as a further control in this study.

Ten cases were studied. The coefficient of digestibility of fat was determined and found to range from 98 to 79 per cent, the average being 90 per cent. The normal coefficient of digestibility of butter fat is 97 per cent.

This study shows:

(1) Fat absorption may be normal even though there is non-visualization of the gallbladder.

(2) Cholecystic disease, without obstruction of the common bile duct, may be accompanied by diminished absorption of fat; an average in this series of cases is reported of 7 per cent, with one observation 18 per cent, below normal efficiency.

Antibody Response of Human Subjects to Intracutaneous Injections of Pneumococcus Carbohydrates. By Maxwell Finland and HARRY F. DowlING (introduced by William B. Castle), Boston, Mass.

Minute amounts of various carbohydrate fractions of Type I, II and III pneumococci were injected intracutaneously in normal individuals and in hospital patients free from recent infections. The soluble specific substances (Heidelberger, Goebel and Avery) and the cellular carbohydrates (Wadsworth and Brown) of virulent Type I, II and III strains and the cellular carbohydrates of a degraded, avirulent and non-type-specific strain derived from a virulent Type I strain were used. These were injected singly and in groups. 
Single injections and repeated injections at intervals were used in different subjects. The blood of the subjects was tested before and at intervals after such injections for various immunological reactions to virulent Type I, II and III pneumococci. Type-specific opsonins, agglutinins and protective antibodies in varying degrees developed as a result of the injections. Only minor differences were observed between the serological immunity resulting from the soluble specific substances and that resulting from the cellular carbohydrates.

The Cerebral Circulation. XXXI. The Effect of Alcohol upon the Cerebral Vessels. By Caroline C. Bedell (by invitation) and Stanley CobB, Boston, Mass.

The effect of alcohol on the calibre of pial arteries was studied by the method described by Forbes ${ }^{1}$; a window was screwed into the skull of a cat and the arterial diameter measured microscopically with a micrometer eyepiece. Fifteen cats under Dial ("Ciba") anesthesia were given 34 injections of 25 per cent alcohol; significant arterial dilatation resulted in 28 instances. The average dilatation was 19.5 per cent, reaching a maximum 4 minutes after starting the injection. In 62 per cent of the trials, a brief constriction averaging 7.1 per cent occurred one minute after the injection was started. The dilatation was roughly proportional to the size of dose and rate of injection, and quite independent of changes in systemic blood pressure. An increase in cerebrospinal fluid pressure was consistently noted, beginning shortly before the vessel under observation dilated. Simultaneous measurements of cerebral blood flow obtained with Gibb's flow recorder ${ }^{2}$ gave added evidence of greatly increased cerebral circulation during the period of vasodilatation.

Intracarotid injection of alcohol in much smaller dosage produced an average dilatation of 35 per cent in 12 out of 13 trials, with little or no change in systemic blood pressure. Alcohol administered by stomach tube to anesthetized cats was not followed by vasodilatation, but in a cat observed after full recovery from anesthesia the artery dilated 16 per cent in 23 minutes, returning to normal 26 minutes later.

\section{The Nature and Action of a Pressor Substance Found in Body Fluids of Man.} By Irvine H. Page (introduced by A. E. Cohn), New York, N. Y.

Extracts of human blood plasma, ascitic and cerebrospinal fluids contain a substance which has a powerful pressor action. The plasma colloids appear to hold it in a bound state. Coagulation alone of the blood does not cause the substance to be formed. Its action suggests that its pressor effect is brought about by mediation of the central nervous system. The rise in pressure of the test animal is due especially to constriction of the arteries in the splanchnic region.

Assay of the pressor extract is made difficult because of the dependence of the vascular response on the functional state of the central nervous system. No evidence has been obtained indicating that these substances are increased in amount in patients suffering from hypertension of varied pathogenesis. Extract of the ventricular and spinal fluids and urine of certain patients has much greater vaso-activity than normal.

The pressor action of extracts of human body fluids appear to be a phenomenon which is species-specific.

\footnotetext{
${ }^{1}$ Forbes, H. S., Arch. Neurol. and Psych., 1928, 19, 751.

2 Gibbs, F. A., Proc. Soc. Exper. Biol. and Med., 1933, 31, 49.
} 
The belief that in cases of nephritic hypertension some substance is present in plasma which sensitizes the blood vessels to epinephrin receives no support from studies on pithed cats.

A Photoelectric Method for the Measurement of the Number of Red Cells and Hemoglobin Concentration in the Same Small Sample of Blood. By Ronald V. Christie and (by invitation) Kenneth A. Evelyn, Montreal, Canada.

The apparatus is essentially a photoelectric opacity meter consisting of a light source, adjustable filter, absorption cell, photoelectric cell and galvanometer. The light source is a 2 c.p. 6 volt bulb in a parabolic reflector. The conventional rectangular glass absorption cell is replaced by a test tube which also serves as a cylindrical lens to focus the light on the photoelectric cell. A vacuum alkali cell is used for maximum stability.

A filter which transmits only the red end of the spectrum (in which region absorption by hemoglobin is negligible) is inserted, $0.05 \mathrm{cc}$. of blood is diluted to $10 \mathrm{cc}$. in the absorption tube and is further diluted until the opacity falls to a value which corresponds to a known concentration of erythrocytes of normal size. The erythrocyte concentration is calculated from the dilution required. The cell diameter is measured on a halometer attached to the apparatus and a correction appplied if necessary; the correction for size is negligible except in extreme cases.

The sample is then laked with saponin, the filter changed to transmit a band including both the main hemoglobin bands, and the hemoglobin concentration is measured as with any other photoelectric hemoglobinometer.

Errors in the erythrocyte count are \pm 5 per cent, in the hemoglobin concentration \pm 2 per cent. The technique is simple, the apparatus inexpensive and the entire determination requires 4 minutes.

Splenectomy for Acute Hemoclastic Crises. By Chardes A. Doan (by invitation), George M. Curtis and Bruce K. Wiseman (by invitation), Columbus, Ohio.

Splenectomy, performed in patients with hemolytic jaundice, is followed at once by a definite increase in the erythrocytes and hemoglobin. This ensues immediately after operation and amounts, essentially, to a spontaneous autotransfusion. Investigations made during the past three years on twenty-four clinical cases occurring in eight families have resulted in therapeutic splenectomy in eight individuals. Prompt relief from the principal symptoms of the disease ensued in each instance. It appeared that the spleen was the main etiologic factor in the production of the hemolytic syndrome.

Acute hemoclastic crises occur at intervals in the course of the disease. They may be precipitated by various causes, such as fracture or other injury, intercurrent disease or by major surgery. It is the usual teaching that splenectomy should not be carried out during a crisis. On the other hand, our investigations have led us to conclude otherwise. Splenectomy has been performed four times during spontaneous or induced acute hemoclastic crises. One of these patients was a four year old girl with 800,000 red cells and 100 per cent reticulocytes. In each of these patients, the characteristic autotransfusion ensued immediately after the splenectomy, with complete recovery following in due course. 
Observations on the Autonomic Control of Cardiac Vasculature. Attempted Vagus. and Sympathetic Overaction on Cat's Heart. By Harold F. RoBertson and Arthur J. Derbyshire (by invitation) and Elliott C. CutLER, Boston, Mass.

In some cats unilateral or bilateral division of the sympathetic or parasympathetic innnervation to the heart or of both was carried out. In other cats unilateral or bilateral suture of the cephalic end of the phrenic nerve to the caudal end of either the cervical sympathetic trunk or the vagus nerve was done, the opposing innervation to the heart being cut in a few of these cases. Animals were examined for changes in cardiac function and in cardiac response to drugs. Anastomosed nerves were tested periodically with an amplifier and loudspeaker to ascertain whether typical phrenic impulses were carried caudad from the site of suture and to what location. At the same time the heart could usually be inspected. As occasion arose, autopsies were done and sections made to study the cardiac vessels and to determine the courses and terminations of the anastomosed nerves.

Neither denervation nor nerve suture has produced, after many months, any cardiac change. Electrical evidence, checked histologically, has demonstrated growth of anastomosed nerves toward the heart. There has been no functional or anatomic evidence that autonomic end-organ or synaptic anastomoses with the down-growing phrenic fibers have taken place.

Some Responses of Normal Kidneys to the Intravenous Injection of Parathyroid Extract. By REAd Ellsworth and (by invitation) JOH N EAger HowARD, Baltimore, Md.

Individuals in whom the kidneys gave evidence of functioning normally were kept fasting, at rest, and on a given fluid intake. Urine was collected hourly for three hours before and three hours after the intravenous injection of 40 units of parathormone. Following the extract there was usually, but not always, a diuresis. There was no alteration in urea clearance. There was a tendency for the $\mathrm{pH}$ to shift toward the alkaline side. The chloride excretion usually rose very slightly in the first hour after the injection and then decreased quite markedly in the second and third hours. Most striking was the outpouring of phosphate in the urine. This was very conspicuous during all three hours after the parathormone. The phosphate clearance in cc. plasma cleared per hour increased from two to five-fold after the injection.

The phosphorus diuresis was accompanied by a relatively slight fall in serum inorganic phosphate.

A definite effect of intravenous parathyroid extract upon the normal kidney is indicated, most conspicuously apparent in the excretion of phosphate. It is similar to the effect of intramuscular injection in hypoparathyroid patients previously reported.

\section{The Effect of Gastrectomy on the Assimilation of Food. By Edward S.} EMERY, JR., Boston, Mass.

This study was stimulated by observing a patient who developed a steatorrhea following a subtotal gastrectomy. The object of the investigation was to determine the effect of removal of the stomach on the assimilation of food and to investigate the reasons for any failure of assimilation. The method of study consisted of feeding dogs weighed amounts of food and comparing the amounts of carbohydrate, protein and fat ingested with the amounts lost through the 
stools. A control series was obtained on five normal dogs, and studies were made on two dogs with a complete gastrectomy. The outstanding finding was a markedly deficient utilization of fat. The utilization of nitrogen was only slightly impaired, and carbohydrates were assimilated normally. Utilization of fat was not improved by the administration of hydrochloric acid, raw pancreas and pancreatic ferments, bile salts or fatty acids. It was definitely improved by small feedings at frequent intervals. The data suggest that removal of the stomach interferes with the utilization of fat because of the loss of the stomach's function of distributing food to the intestine according to the physiological requirements of the latter.

Observations on a Case of Paroxysmal Hemoglobinuria. By A. Carlton ERnStene and (by invitation) W. James Gardner, Cleveland, Ohio.

A study has been made of a case of paroxysmal hemoglobinuria in a man who presented no clinical or laboratory evidence of syphilis. The Donath and Landsteiner reaction for the presence of hemolysin in the blood serum was consistently positive. Spontaneous attacks of hemoglobinuria occurred after exposure to temperatures as high as $52^{\circ} \mathrm{F}$. and were accompanied by deep cyanosis of the fingers, toes, nose and ears. Hemoglobinuria could be produced regularly by the application of ice packs from the feet to the level of the anterior superior spine of the ilium or to the xiphoid process for twenty minutes or longer. After spinal anesthesia extending to the nipple line, however, ice packs did not cause hemoglobinuria, nor did hemoglobinuria occur when spinal anesthesia was followed by exposure of the entire body to a temperature of $51^{\circ} \mathrm{F}$. for one hour. Injection of novocaine into both lumbar sympathetic chains did not prevent the production of hemoglobinuria by ice packs.

In view of these observations, it was decided to resect the left splanchnic nerves and remove a portion of the left lumbar sympathetic chain. The patient remained in the hospital for three weeks after the operation, and during this time several attempts to induce hemoglobinuria with ice packs failed without exception. The Donath and Landsteiner reaction was repeated on the fifteenth, eighteenth and twenty-fifth days after operation and was negative on each occasion. Soon after discharge from the hospital, the patient reported having passed a single specimen of red urine after remaining out-of-doors for nearly three hours at a temperature of $18^{\circ} \mathrm{F}$. Attempts to produce hemoglobinuria with ice packs were unsuccessful at that time. One month later, however, ice packs regularly induced attacks. A second operation, therefore, was performed in which the right splanchnic nerves were severed and the second and third lumbar sympathetic ganglia removed. Subsequent attempts to produce hemoglobinuria with ice packs have failed. The Donath and Landsteiner reaction has remained negative since the first operation. The observations suggest that paroxysmal hemoglobinuria is due fundamentally to a disturbance of the sympathetic system, at least in cases not associated with syphilis. They also indicate a promising approach to the treatment of the condition.

The Continued Administration of Large Amounts of Irradiated Ergosterol to Patients Suffering from Postoperative Parathyroid Tetany: Its Therapeutic Value and Effect on Calcium and Phosphorus Metabolism. By R. F. FARQuharson, Toronto, Ont.

A number of patients suffering from post operative parathyroid tetany have been treated with very large doses of irradiated ergosterol for prolonged periods during the past two years. In all cases over periods of from three to four 
weeks, the serum calcium could be raised to normal, the urinary excretion of calcium increased, and the tentany relieved by the oral administration of a concentrated solution of irradiated ergosterol in amounts equivalent to 20 to 60 cc. of commercial viosterol daily. The effect of such administration might last for one month or more after cessation of therapy. In one case, after almost continuous administration of large doses for nearly two years, the continued ingestion of a much larger dose failed to relieve tetany completely or to increase the serum calcium materially.

The effect of such prolonged treatment on the serum calcium and phosphorus and the excretion of calcium and phosphorus in the stools and urine of a control patient as well as of patients with parathyroid tetany is reported.

\section{Fusospirochetal Pneumonia. By Henry Field, Jr., Ann Arbor, Mich.}

The importance of the fusospirochetal group of organisms in chronic lung diseases, particularly lung abscess and bronchiectasis, has become increasingly apparent. While it has been recognized that these end states are preceded by a pneumonic stage, fusospirochetal pneumonia has not been adequately recognized and described. Our observations lead us to believe that it is comparatively common and that it has distinctive features which make it a clinical entity.

Although sometimes fairly acute and severe, it is commonly subacute to chronic, with mild fever and little cough or sputum in the presence of extensive consolidation. The sputum is commonly not foul. The x-ray appearance is somewhat characteristic, particularly the slow progression and regression of consolidation which may not correspond with the course of symptoms. There is usually complete or nearly complete resolution of consolidation and symptomatic cure, although asymptomatic bronchiectasis or abscess is a frequent residual. Bronchiectasis has been demonstrated by lipiodal instillation six weeks after onset, and nearly complete resolution, without appreciable bronchiectasis, has occurred after nine months.

The effect of arsphenamine treatment has been carefully observed. The fusospirochetal organisms have persisted in the sputum following its administration in intensive doses. A spread of consolidation and fusospirochetal gingivitis have been observed soon after its administration. Its effectiveness needs further confirmation.

A Study of Fat Tolerance Tests. By HARRY Blotner (by invitation) and Reginald Fitz, Boston, Mass.

A group of patients has been given an oral test meal of 500 cc. of 20 per cent fat and the blood cholesterol has been estimated at two-hourly intervals thereafter for eight hours. Certain bizarre results of some interest have been obtained. The normal individual's blood fat remains essentially constant. An obese person's or a person's with diabetes insipidus shows a progressive rise in the blood cholesterol concentration and this rise can be sharply inhibited by the use of posterior lobe pituitary extract. Insulin appears to cause a rise in the concentration of blood cholesterol in normal individuals receiving insulin as a means to induce gain of weight. These observations add further evidence to demonstrate the antagonistic effect of insulin and posterior lobe pituitary extract and they suggest further that obesity may be definitely related to the pituitary gland and that in certain cases obesity has an endocrine background as its basis. 
Changes in Specific Gravity, Total Nitrogen, and Colloid Osmotic Pressure of the Plasma in Normal and Edematous Dogs following Salyrgan. By Marshall N. Fulton and (by invitation) A. H. Bryan, William Evans, JR., and E. A. Stead, JR., Boston, Mass.

Studies have been made in normal dogs following the administration of water which indicate that measurements of the specific gravity, total nitrogen, and colloid osmotic pressure of the plasma may be used as an index of dilution or concentration of the blood. In search of evidence of the extrarenal action of salyrgan, similar measurements were made in normal dogs after administering salyrgan intravenously. To secure a much greater diuretic response, the animals were then made edematous by plasmapheresis plus the feeding of salt. Under these conditions, salyrgan causes a diuresis 15 to 20 times as great as that observed in normal dogs. The urine flow may amount to as much as $11 \mathrm{cc}$. per minute for a half hour period which is comparable to 50 or $60 \mathrm{cc}$. per minute in man-a diuresis which should be suitable to furnish evidence of an extrarenal action of this drug. Measurements made each hour during such a diuresis of the specific gravity and nitrogen concentration of the plasma and at various intervals of the colloid osmotic pressure of the plasma do not indicate any dilution of the blood preceding the diuresis. On the contrary, during the course of the diuresis and apparently as a result of it, there occurred measurable changes in these factors which indicate an actual blood concentration. Such findings suggest a renal effect as the chief if not the sole cause of diuresis following salyrgan.

The Value of Abdominal Compression in the Treatment of Chronic Pulmonary Tuberculosis with Cavitation. By Burgess L. Gordon, Philadelphia, Pa.

It was shown in previous studies that elevation of the diaphragm due to abdominal tumors decreased the extent and activity of tuberculous lesions. This suggested the use of abdominal compression for the treatment of tuberculosis. Special abdominal supports were devised and the indications studied. Roentgenograms of the lungs show a marked decrease in cavitation in fibroid cases; improvement in cough, dyspnea and expectoration were striking. The mechanism has been considered.

Clinical and Pathological Observations on the Heart in Trichinosis. By WesLEY W. SPINK (introduced by Clark W. Heath), Boston, Mass.

Two cases of severe trichinosis were studied with special attention to a complicating myocarditis. The first patient entered the hospital with the typical clinical picture of trichinosis. Examination of the heart revealed a gallop rhythm and tachycardia. Arterial hypotension also occurred. On the sixteenth day of the disease, the electrocardiogram showed T-1 and T-3 inverted and T-2 inverted with upward convexity. The same changes were present four days later. Four weeks later the electrocardiogram was interpreted as normal.

The second patient died forty-eight hours after he was first seen. At postmortem examination death was attributed to a severe myocarditis and bronchopneumonia. Microscopic examination of sections of heart muscle revealed no larvae. After peptic digestion of the whole heart, fourteen larvae were found in the sediment. They were of the size usually found in skeletal muscle and not the smaller forms found in the circulating blood, thus excluding the possibility of their presence in the blood vessels of the heart.

Doubt exists in the medical literature as to whether the myocarditis of trichinosis is due to the presence of the parasite or to blood-borne "toxins." 
Clinical reports have not included electrocardiographic observations. The myocarditis of trichinosis may result from an invasion of the muscle by the parasite. The lesion occurs as early as the second week of the disease as observed in electrocardiographic and clinical studies, and may be the cause of death in the sixth week.

\section{The Analgesic Effect of Jaundice on the Rheumatic State. By Prilip S.} HeNcH, Rochester, Minn.

About twenty-five patients with different kinds of "chronic rheumatism" (arthritis, fibrositis, sciatica, sciatic pain) have been seen who have developed intercurrent jaundice. During the jaundice and for variable periods thereafter the majority of patients were " completely cured," and there was either complete or marked amelioration, not only of pain, but of stiffness and soreness, and in some cases of swelling. This paper presents the clinical data on these cases, the types of jaundice concerned, the relationship between the serum bilirubin and the van den Bergh and the degree of analgesia experienced, considerations of the mechanisms involved, and experimental attempts to repeat the analgesic effect.

The Peripheral Vascular Effects of Freezing and the Amelioration by an Intermittent Negative Pressure Environment. By LouIs G. HerRmañ (by invitation), and George Herrmann, Galveston, Texas.

The pathologic physiology of the circulation of blood in the ears of a series of hares after various degrees of freezing caused by the application of carbon dioxide snow, liquid air, ethyl chloride spray or natural cold, was studied in detail. The early constrictor effect of cold was found to be of short duration. Curves showing this effect will be demonstrated. The second or important stage, i.e. capillary stasis, was likewise studied. When capillary stasis was permitted to remain unchanged for several hours, disintegration of the cellular elements of the blood took place and the blood in the arterioles, capillaries and venules coagulated. In the untreated animals gangrene resulted. At the stage of capillary stasis in another series of animals, the affected ears were treated by rhythmic alternation of the environmental pressure from about $50 \mathrm{~mm}$. of mercury negative pressure to about $20 \mathrm{~mm}$. of positive pressure at the rate of 4 cycles per minute. A special treatment jar of glass was constructed in order that one ear could be treated and observations be made without influencing the circulation of other parts of the animal's body. Restoration of the arterial circulation resulted after 20 minutes of such treatment and gangrene was prevented. A clinical case of bilateral frozen feet was treated in this manner and within 12 hours the arterial circulation was reestablished in both feet. Only slight necrosis of the skin of four toes resulted. Photographs and charts will illustrate the experimental and clinical basis for this form of therapy.

Acute Lead Poisoning Experimentally Produced. By Bayard T. HoRTon and (by invitation) J. Arnold Bargen, and ARnold E. Osterberg, Rochester, Minn.

During the past three years, while attempting to treat with lead subjects with inoperable cancer, we have had an unusual opportunity to observe the development of early signs and symptoms of acute lead poisoning. Eighty-one subjects received 476 intravenous injections of either colloidal lead phosphate or lead selenide. Each subject received an average total dose of $440 \mathrm{mgm}$. of lead. Immediately, fever, chills, generalized aches and pains, nausea or vomit- 
ing occurred in 101 instances, 21 per cent). These symptoms promptly disappeared. Approximately two weeks after completion of the treatment, 44 subjects developed signs and symptoms of acute lead intoxication which consisted of general malaise, weakness, headaches, generalized aches, shooting pains in the extremities, abdominal cramps, nausea and vomiting, blue gums and sallow complexion. These features persisted from two weeks to three months. Wrist drop and toe drop were observed only in one subject. Patients varied markedly in their tolerance to lead as illustrated by its effect on the erythrocytes and its excretion in the urine. When lead was excreted in the urine, it was in small amounts $(0.1 \mathrm{mgm}$. to $0.2 \mathrm{mgm}$. each day) with no relationship to the amount previously administered. The spleen and liver were rendered roentgenologically visible.

Inadequate Amount of Gastric Secretion as a Factor in the Production of Pernicious Anemia. By Raphael IsaAcs and S. M. Goldhamer (by invitation) and C. C. Sturgis, Ann Arbor, Mich.

The average amount of secretion of gastric juice, with or without histamin injection, in 63 collections in 10 patients with pernicious anemia was $20 \mathrm{cc}$. per hour as compared with about $150 \mathrm{cc}$. per hour in normal individuals under the same conditions. Gastric secretion collected from untreated patients with pernicious anemia was incubated with ground beef. This, in amounts comparable to that secreted by normal individuals, was then fed daily to two patients with pernicious anemia. Data on the blood changes which followed are given. The response suggests that the gastric secretion in pernicious anemia may have the precursor of the hematopoetic stimulant, but, because of the defective amount secreted, may not be able to raise the blood count above a certain minimal level.

The Characteristics of the Synovial Fluid in Gonococcal Arthritis. By WaLter K. Myers and William F. Holmes, Jr. (by invitation) and Chester S. KeEFER, Boston, Mass.

In order to gather more precise information regarding the characteristics of the synovial fluid in gonococcal arthritis, 54 samples from 40 patients were studied. Total and differential leukocyte counts were made on the fluid, and the total protein, sugar and nonprotein nitrogen content of the fluid was compared with that of the blood. Gonococcal complement fixation tests and bacterial cultures were made at the same time. The fluids were divided into two groups-the uninfected and the infected. The results were as follows:

The total leukocyte count was somewhat higher in the infected fluids; the polymorphonuclear cells were present in greater numbers and the monocytes and clasmatocytes in fewer numbers than in the uninfected fluids.

The total protein was increased in both, varying from 3.5 to 6.0 per cent. The nonprotein nitrogen content was the same in the blood and synovial fluid. The sugar content of the fluid depended upon three factors: the level of the blood sugar, the number of leukocytes and the presence of organisms; of these, the first two were more important than the third.

Gonococcal complement fixation reactions were the same in the joint fluid as in the blood serum, and were positive in 74 per cent of the cases.

The examinations of most value were the total and differential counts, and the bacteriological and serological examinations. Chemical examinations yielded very little of either diagnostic or prognostic value. 
The Effect on the Heart of Experimental Pleural Conglutination. By HoRACE M. Korns and (by invitation) HarRy Landt, O. R. Hyndman, Raymond Gregory, and Clark N. Cooper, Iowa City, Iowa.

Revival of the Human Heart. By W. B. Kountz and (by invitation), M. Prinzmetal, St. Louis, Mo.

A method by which the human heart may be revived soon after death has been applied to sixty-two bodies. Moving pictures showing details of the method are presented.

The important feature of the apparatus is that it maintains a constant pressure relationship in the ventricle and in the coronary system. Details are shown from the initial autopsy incision to the demonstration of the beating heart together with electrocardiographic tracings taken at intervals during the period of revival. This method permits the study of a number of physiological problems which can be attacked by no other means. The right and left bundle branches of the revived heart have been cut and extrasystoles have been produced at different points. A record of the results will be shown.

Recurrent Agranulocytosis. By Doran J. Stephens (by invitation) and JoHn S. LAWRENCE, Rochester, N. Y.

Detailed observations have been made over a period of eighteen months in the case of a 47-year old woman who has had thirteen attacks of recurrent granulocytopenia. During the first five months of observation there were five periods of neutropenia three of which were accompanied by infection of the upper respiratory tract. Each period of neutropenia coincided with a menstrual period. Sternal biopsy showed an essentially normal bone marrow. Bilateral oophorectomy was done, following which there was a modification of the neutropenic cycle. Estimations of urinary excretion of female sex hormone were made before and after operation. The administration of theelin was without apparent effect on the neutropenic cycle. Satisfactory remissions of individual attacks of granulocytopenia were observed with and without the use of pentnucleotide.

In control experiments, white blood cell counts and differential counts of six normal young women were studied over a period of two months. There was no significant change in the white blood cell picture at the time of the menstrual period.

The Calorigenic Action of the Optically Active Isomers of Thyroxin. By J. Lerman and W. T. Salter, Boston, Mass.

For many years it has been known that pure racemic thyroxin is less active than crude thyroid extract in the same thyroxin iodine dosage. Optical activity and peptide linkage have been suggested as explanations. In a previous report to this Society, natural thyroxin polypeptide was shown to have only the activity of racemic thyroxin and of whole gland administered in equi-iodine dosage. Since then, both $d$ - and 1 - thyroxin (donated by Harington) have been tested in five patients with myxedema and found to yield identical results when administered intravenously in daily rations. The calorigenic responses check the standard polypeptide curve, previously reported.

In normal rats, 1-thyroxin has been shown by other authors to be three times as active as the $d$ - isomer. It is inferred that the relatively large dosage employed in such experiments constituted a pharmacological observation rather 
than a physiological effect. Moreover these experiments were conducted on animals possessing intact thyroid glands-a condition which prevents the proper evaluation of results.

The present data substantiate the previous inference that thyroxin is not the only active constituent of thyroglobulin.

The Action of Injected and Secreted Adrenalin Before and After Total Thyroidectomy. By Morton G. Brown and Margaret M. Sawyer (by invitation) and SAmuel A. Levine, Boston, Mass.

The sensitivity to adrenalin as indicated by the rate of the denervated heart was studied in two groups of cats. In the first group of cats the hearts were denervated. The adrenals were then stimulated in two ways. First, the cats were put in a cold room at $1^{\circ} \mathrm{C}$. for 45 to 60 minutes. Secondly, the cats were made to run on a treadmill at a constant rate for a given length of time. The increase in heart rate caused by this stimulation was noted. Total thyroidectomy was then performed and it was found that the rate response to these stimuli was only about 50 per cent of the preoperative response. The preoperative response could be restored by increasing the metabolism by feeding thyroxin.

In the second group of cats the adrenals were inactivated as well as having the hearts denervated. A given amount of adrenalin of standard strength was then injected intravenously and the increase in heart rate was noted. These cats then had a total thyroidectomy and it was found that the rate response to the same amount of adrenalin was only about 50 per cent of the preoperative level and could be restored by increasing the metabolism by feeding thyroxin.

We believe that these observations throw some light on the clinical results obtained from total thyroidectomy in the treatment of intractable heart disease.

The Heart in Scarlet Fever. By James M. FAULKNER (introduced by E. A. Locke), Boston, Mass.

The object of the study was to determine the incidence and character of the cardiac involvement in scarlet fever.

A total of 171 cases of scarlet fever were studied during the acute illness. In view of the unreliability of auscultatory findings in the heart in acute infections particular importance was placed on the electrocardiogram. One or more electrocardiograms were taken in each case. Electrocardiographic changes observed were prolonged $P-R$ interval in five cases and $T$-wave changes in five cases. The number of cases showing electrocardiographic changes was ten or 5.8 per cent. In addition, nine cases exhibited a $\mathrm{P}-\mathrm{R}$ interval of 0.20 second, a finding of borderline significance. Cases which developed scarlatinal arthritis showed an increased tendency to electrocardiographic abnormalities. Of 142 cases of scarlet fever without arthritis, eight or 5.6 per cent showed such changes, whereas in twenty-nine cases with arthritis, two or 7 per cent showed them. The difference is, of course, too small to be significant but if we include cases showing a P-R interval of 0.20 second, it becomes more striking, being 9.8 per cent for cases without arthritis and 17.2 per cent for cases with arthritis.

In addition, a follow-up study was made of 600 cases of scarlet fever from one to three years after the acute infection. Of these 600 cases, seven had developed signs of heart disease. In two, the signs of endocarditis had appeared while the patients were still in quarantine. In the third, a typical attack of rheumatic fever occurred immediately after discharge from quarantine. An- 
other suffered from three attacks of rheumatic fever during the interval between the scarlet fever and the follow-up examination. In the remaining three cases, the physical signs of valvular disease were found without any intercedent history of rheumatic fever or chorea. There appeared to be no relationship between the severity of the infection and the subsequnt development of heart disease. None of this group had scarlatinal arthritis. The type of heart developed in these cases was indistinguishable clinically from "rheumatic" heart disease.

The conclusion to be drawn from these observations is that scarlet fever is occasionally the inciting factor in the "rheumatic state." The incidence of heart disease following scarlet fever is small and perhaps no greater than that following simple acute tonsillitis.

The Relation of Fat Oxidation to Phosphocreatine Metabolism and Creatinuria. By Robert O. Loebel, New York, N. Y.

In the light of recent work one might expect a close relation to exist between the muscular weakness of diabetes or of carbohydrate deficiency on the one hand and the creatine phosphate metabolism and creatinuria on the other.

In this study four epileptic patients and one diabetic on creatine-free diets were studied for a period of 1 to 3 months; ketosis being induced in the former by high fat diets and fasting, in the latter by the withdrawal of insulin. Ketonuria appeared before increased amounts of creatine were excreted. The amounts of the latter were much smaller than has been observed (under somewhat different conditions) by previous workers who did not distill off the ketone bodies before determining the creatinine.

The ketonuria produced little or no change in creatine tolerance (the amount of ingested creatine which is retained and not excreted).

To interpret these results the synthesis of phosphocreatine (creatine + phophate $\leftrightarrows$ phosphocreatine) was directly measured in the excised muscle of normal and diabetic dogs. In 4 normal dogs the phosphocreatine of the excised muscle was reduced by 20 minutes of nitrogen exposure to an average value of $8.9 \mathrm{mgm}$. $\mathrm{P}$ per 100 grams of muscle. When the muscle was allowed to respire for 2 hours at $37.5^{\circ} \mathrm{C}$. in pure oxygen in a solution of buffered saline containing 0.2 per cent glucose the phosphocreatine reached a value of 30.5 mgm., i.e. 240 per cent increase over the original value.

Under the same conditions the muscle of 4 depancreatized dogs had an initial phosphocreatine content of $4.5 \mathrm{mgm}$. which increased to $21.8 \mathrm{mgm}$. after 2 hours in oxygen, i.e. an increase of 260 per cent. Simultaneous determinations of the respiratory quotient of the excised diabetic muscle averaged 0.73 , i.e. practically complete diabetes.

In the presence of fat oxidation, therefore, a synthesis of phosphocreatine occurred which approaches, or even equals that taking place in the presence of carbohydrate oxidation.

Studies on Minute Hemolytic Streptococci. II. The Distribution of Minute Hemolytic Streptococci. By PERrin H. Long and (by invitation) Eleanor A. Bliss, and Charles F. Wolcott, Baltimore, Md.

Recently we have described the occurrence of minute beta hemolytic streptococci in the rhinopharynges of individuals ill with diseases in which beta hemolytic streptococci are generally considered to be of etiological significance.

In this report we propose to discuss the distribution of these minute or- 
ganisms in normal individuals and in those ill with glomerular nephritis, scarlet fever, and progressive rheumatic infection and to consider their possible significance in certain phases of these diseases.

The Significance of the Serum Iron in Certain Types of Anemia. By J. F. McINTosh, Montreal, Canada.

Fontès and Thivolle, Warburg and Krebs, have shown that the serum iron is decreased in experimental anemias, in the horse, and in birds respectively.

These findings have been confirmed in the dog. After bleeding, the serum iron fell from 0.17 to $0.08 \mathrm{mgm}$. per cent, and remained low throughout the period of hemoglobin regeneration. After the latter had reached a normal figure, the serum iron returned to its initial value.

In cases of hypochromic anemia, the initial values may be low. During iron medication, the hemoglobin values tend to rise first, the serum iron later. Just as in experimental anemia, narrow fluctuations in the hemoglobin are accompanied by wide changes in the serum iron.

In an untreated case of pernicious anemia, a high initial value of $0.24 \mathrm{mgm}$. per cent was found. During the reticulocytosis produced by liver extract, the value fell to $0.04 \mathrm{mgm}$. It rose gradually as treatment was carried on.

The serum iron appears to represent a balance between hemoglobin synthesis, and the iron which is available from food and iron depots.

\section{A Comparison of the Tuberculous and Chronic Non-tuberculous Pulmonary Infiltrations of Childhood as Regards Age-Incidence, Anatomical Dis- tribution and Course. By F. M. McPhedran, Philadelphia, Pa.}

In a pathogenetic study during the past eleven years serial $\mathrm{x}$-ray observations have been made on three groups of families: (1) tuberculous, (2) normal controls, (3) families having a high incidence of chronic non-tuberculous pulmonary lesions. Both tuberculous and non-tuberculous infiltrations predominate in certain families, but after infancy the two lesions diverge widely in incidence and severity. From the third to the eleventh year severe tuberculous lesions are rare, while non-tuberculous bronchopneumonia, particularly chronic or relapsing bronchopneumonia causes severe illness. Towards puberty non-tuberculous lesions decrease both in extent and in the illness they cause. At the same time there begin to appear the dangerous tuberculous lesions of the adult type. During childhood the non-tuberculous lesions predominate in the lower third of the lung and are densest close to the cardiophrenic angle. The tuberculous lesions develop chiefly in the middle third and are based on the peripheral pleura. Excavation, if it occurs, is usually on the posterior wall. Nontuberculous infiltrations appear not to intensify co-existing tuberculous lesions.

Having regard to the total of chronic non-tuberculous bronchopneumonias, bronchiectasis is relatively rare.

On a Pernicious Anemia-Like State in the Guinea Pig. By B. M. JAcoBson (introduced by J. H. Means), Boston, Mass.

It has been found, in the investigation of several laboratory animals, that certain guinea pigs respond to the administration of therapeutically active commercial liver extracts with a reticulocytosis. Such guinea pigs are termed reactive animals; they maintain this state indefinitely. The minimum amount of material which evokes a positive reticulocyte response is the liver extract derived from approximately $0.6 \mathrm{mgm}$. of fresh porcine liver, per kilogram of 
guinea pig. This is defined as the Guinea Pig Unit (G.P.U.) of hematopoietic activity. One hundred grams of fresh porcine liver may be said to contain approximately 164,000 G.P.U.

The pernicious anemia-like state in the reactive guinea pig is evidenced by the following phenomena. (1) Therapeutically potent commercial liver extracts show quantitatively similar activity in the guinea pig. On the other hand, numerous pure inorganic and organic substances, as well as crude mixtures obtained from biological materials, which are all inert in pernicious anemia, are likewise inert in the guinea pig. Further control data are furnished by the fact that although the liver of a non-anemic patient, when assayed on the guinea pig, showed an activity of 164,000 G.P.U. per 100 grams, the liver of a patient, who died of pernicious anemia, exhibited an activity of less than 12 G.P.U. per 100 grams. (2) The liver of the reactive guinea pig is deficient in hematopoietic activity, for such a liver has shown a potency of only 23,000 G.P.U. per 100 grams, while the liver of a non-reactive animal one of 164,000 G.P.U. per 100 grams. (3) Finally, the reactive guinea pig responds to the administration of a mixture of Castle's intrinsic factor (normal human gastric juice) and extrinsic factor, with a reticulocytosis; whereas inactivation of the intrinsic factor by heat results in the guinea pig, as in pernicous anemia, in a negative response.

It is therefore believed that the reticulocytosis induced in the guinea pig by commercial liver extracts is related to the same phenomena in pernicious anemia.

Further Observations on Chronic Idiopathic Hypochromic Anemia. The Effect upon Formation of Erythrocytes of Administering Small Doses of Inorganic Iron in an Acid Medium as Compared to Predigested Food with Special Reference to Beef Muscle. By Stacy R. Metrier and (by invitation) Frederick Kellogg, San Francisco, Cal.

Previous studies on patients with achlorhydria and chronic hypochromic anemia showed increased formation of blood following the daily administration of a meal that had been predigested in vitro with strong $\mathrm{HCl}$ and pepsin. The acidity was adjusted to $\mathrm{pH} 4$ before feeding. The response was similar to that induced by large doses of inorganic iron. The meal (i.e., 300 grams of lean beef muscle, 200 grams of spinach and 2 soft boiled eggs) when ashed contained approximately $12 \mathrm{mgm}$. of iron. It was believed the effect induced was due to the organic iron of the food. Inorganic iron in such small daily doses is ineffective in this type of anemia. In the present study it was decided to determine whether or not the utilization of a very small dose of inorganic iron could be influenced by buffering it to an acid $\mathrm{pH}$ upon the addition of $\mathrm{HCl}$, sodium citrate and a simple protein poor in iron, i.e., gelatin.

In addition it was decided to ascertain whether or not a predigested meal, consisting only of beef muscle meat, would influence blood formation favorably.

A series of patients were given daily, for 10 to 14 days, feedings of 13 or even $25 \mathrm{mgm}$. of inorganic iron with 50 grams of gelatin, the hydrogen-ion concentration of which was adjusted to $\mathrm{pH} 4$ with the addition of $\mathrm{HCl}$ and 10 grams of sodium citrate. At the end of this time a second period was started when the predigested meal (see parenthesis above) was fed. No response in hematopoiesis was induced by the inorganic iron-gelatin combination, but the blood returned to within normal limits on the predigested meals.

In another series of experiments 200 grams of predigested beef muscle was fed daily during the first period and increased to 400 grams in the second period. 
The smaller feedings of beef muscle failed to affect hematopoiesis but an increase in hemoglobin formation occurred after the larger feedings.

Apparently inorganic iron in small amounts in an acid medium with a simple protein has no effect on blood formation in contrast to a predigested meal containing a comparable amount of organic iron.

It is believed these studies give further support to the hypothesis that gastric dysfunction leads to the development of anemia in patients with chronic idiopathic hypochromic anemia.

Clinical Experiences with Thevetin, a Cardiac Glucoside. By Harry ARNold, Honolulu, William S. Middleton, Madison, Wisconsin and K. K. Chen, Indianapolis, Indiana.

The toxicity of be-still nuts, the fruit of Thevetia neriifolia, or the yellow oleander, has been recognized for many years. The digitalis-like action of thevetin has recently been thoroughly studied by Chen and Chen. This glucoside acts more promptly, but is less persistent in its cardiac effects than digitoxin. The cat unit for thevetin was established by Chen and Chen as $0.85 \mathrm{mgm}$. per kilogram or about one-seventh of the potency of ouabain.

Clinical trial of thevetin has been pursued with results justifying continuance. In all instances the theoretical digitalis tolerance has constituted a guide for dosage and the level of five cat units at a single intravenous dose and ten cat units in the twenty-four hours has not been exceeded. The subjective and objective evidences of decompensation have been regularly controlled, as a rule before the appearance of the earlier gastrointestinal manifestations of toxemia, such as anorexia and nausea. The pulse has been slowed more in patients with auricular fibrillation than in those with normal rhythm. A single subject suffering from auricular paroxysmal tachycardia showed no slowing of the rate under thevetin. Electrocardiographic changes parallel those of ouabain.

Experimental Study of Clinical Vitamin $B$ Deficiency. By Katharine O'Shea Elsom (introduced by T. Grier Miller), Philadelphia, Pa.

It is commonly believed that mild vitamin B deficiency occurs only very rarely in man and that for such deficiency to develop at all, the diet must be grossly restricted, as it is in beriberi, or that gross gastro-intestinal disease must exist which interferes with the absorption of food. Observation of patients encountered in the Gastro-Intestinal Section of the University of Pennsylvania Hospital made it seem possible that this belief might be erroneous. Accordingly, a clinical experiment was devised to determine the effects upon man of a moderate restriction of the vitamin B complex, to determine the clinical signs of mild vitamin $B$ deficiency and to ascertain the relative importance of various fractions of the $B$ complex in relief of such deficiency.

This paper reports the results obtained when a patient whose symptoms were suspected of being due to habitually inadequate diet was placed for one year on a diet from which the major vitamin B containing foods were removed but which was adequate in every other known dietary requirement. Protein, caloric and fluid intakes were kept constant, the patient being under careful supervision in the hospital throughout the entire time of observation. After 5 months on the experimental diet various fractions of the vitamin B complex were added in series. Separate preparations were made of vitamins $B_{1}$ and $B_{2}$. $A$ powdered brewer's yeast concentrate was used as a source of additional $B$ factors. Prominent symptoms which became exaggerated during the five months when the patient received the experimental diet without added vitamin 
fractions were: fatigue, anorexia, epigastric distress, constipation, sore tongue, pains and parethesias in the extremities. The most striking physical signs were: loss of weight, development of smooth tongue and of pitting edema of the extremities, the loss of vibratory sensation in the lower extremities and exaggeration of reflexes. Detailed studies were made of the weight loss, the edema, the alterations in total serum protein, the slight anemia and the evidences of impaired cardiovascular and gastro-intestinal functions which developed during the deficient period. Some improvement was observed to take place when separate preparations of vitamins $B_{1}$ and $B_{2}$ were added to the experimental diet. The whole yeast concentrate, however, appeared to be more effective in permanent relief from the symptoms, the physical signs and the evidences of disturbed function which had become manifest during the deficient period.

There are also briefly described similar results which were obtained upon another patient who had for ten years experienced symptoms and physical signs analogous to those which developed in the experimental patient.

Bile Pigment and Hemoglobin Regeneration. The Effect of Bile Pigment in Cases of Chronic Hypochromic Anemia. By Arthur J. Patek, Jr. (by invitation) and George R. Minot, Boston, Mass.

Nine selected patients with chronic hypochromic anemia were studied to determine whether bile pigment could assist in hemoglobin production.

Concentrated bile pigment alone caused not a reticulocyte response but an increase of hemoglobin, about 7 per cent in 10 days. This indicates that in certain anemic patients pigment can be absorbed from the gastro-intestinal tract for building hemoglobin. No further increase of hemoglobin occurred when pigment feeding was continued for longer than about ten days.

After a reticulocyte response occurred to a suboptimal dose of iron, bile pigment was fed directly with the same dose of iron, and there followed a second reticulocyte response. The second response was sometimes of greater magnitude than the first. This indicates that bile pigment in some unknown manner can facilitate either iron absorption or utilization.

One patient, who could not obtain a normal hemoglobin level with large doses of iron, promptly increased her hemoglobin concentration when bile pigment was fed in addition to iron.

It is suggested that in certain cases of hypochromic anemia in addition to iron deficiency there may be a deficiency of a useful material, that is contained in bile pigment.

The Urinary Excretion of Cholesterol and Protein in Bright's Disease. By Maurice Bruger (introduced by H. O. Mosenthal), New York, N. Y.

The paucity of detailed studies in the past of the cholesterol excretion in the urine in Bright's disease and especially of the relation of the cholesterol to the protein excretion prompted this investigation. The cholesterol content of the urine was determined by methods developed in this laboratory in 23 cases of Bright's disease (chronic diffuse glomerular nephritis, 9 cases; chronic diffuse glomerular nephritis with a nephrotic component, 4 cases; amyloid nephrosis, 5 cases; lipoid nephrosis, 5 cases). The protein partition was investigated in all urine specimens and, in many instances, the cholesterol and protein contents of the urinary sediment were also determined. In 9 cases of Bright's disease, the diurnal variations in the urinary excretion of protein and cholesterol were studied. The results indicate that $(a)$ the excretion of choles- 
terol in the urine varies directly with the protein excretion; $(b)$ the cholesterol content of the blood apparently exerts little influence on the concentration of cholesterol in the urine; $(c)$ an increased excretion of globulin in the urine is accompanied by an augmented excretion of cholesterol esters, whereas the urinary excretion of a proportionately greater amount of albumin is generally accompanied by a larger output of free cholesterol; $(d)$ the urinary sediment in Bright's disease is relatively low in protein but the cholesterol content may amount to as much as 30 per cent of the total urinary cholesterol; $(e)$ the concentration of cholesterol and protein in the urine is usually diminished during the sleeping hours, but because of the frequent occurrence of nocturnal polyuria, the total output of these constituents is often greater during this period than in the waking hours.

The Estimation of Changes in Body Fluids. By Paul H. LAvietes (introduced by John P. Peters), New Haven, Conn.

The calculation of water exchange by the method proposed by Newburgh and Johnston and simplified by Peters, Kydd and Lavietes fails to give reasonable results in our hands, probably because in our patients insensible perspiration fails to parallel metabolism and because a practical error of considerable magnitude is incurred in the measurement of dry weight of ingesta and excreta or in the estimation of dietary foodstuffs, or in both. Furthermore at best this method does not distinguish between water exchange in the interstitial fluids and in the cellular fluids.

An independent method of estimating total water exchange from electrolyte metabolism has been devised on the assumption that the concentrations of sodium plus potassium in serum water is approximately equal to and varies with that in body water as a whole. Further, by assuming that practically all the sodium and chloride in the body are restricted to the interstitial fluids and that the concentrations of these electrolytes in these fluids are approximately identical with the concentrations in serum water, changes in interstitial fluid volume may be estimated from the metabolism of either sodium or chloride.

Normal and diseased subjects have been studied during periods of large exchange of water induced by various means. The estimation of total water exchange from sodium plus potassium metabolism in many instances gives more reasonable values than does that derived from Newburgh's method. Furthermore, interstitial fluid exchange calculated independently from sodium and chloride changes shows remarkable agreement in most cases.

The Development of Hypersensitiveness in Man. By Frank A. Simon (by invitation) and Francis M. RackemanN, Boston, Mass.

According to the observations of Hooker, of Park, of Tuft, and more recently of $T$. Duckett Jones, sensitization as determined by a positive skin test can be produced artificially with ease and regularity when diphtheria antitoxin or rabbit peritoneal fluid is injected intracutaneously.

Our own experiments, made with guinea pig serum, confirm the findings of Jones in every way. Furthermore, normal and allergic individuals give the same results. Reactions of the delayed tuberculin type develop after the second or third intracutaneous treatment, whereas reactions of the immediate urticarial type are observed later, after the fifth to seventh treatment. As Jones says, these two reactions represent different phases of the immune process. When the doses were given always into the same spot, the degree of sensitiveness was 
not greater in the reinjected area than elsewhere except in one case. Antibodies in the blood were demonstrated only when the skin reactions became large.

In other experiments, local sensitiveness of the nasal mucosa was produced by repeated packs wet with guinea pig serum. The character and time relation of the nasal response was comparable to the skin response.

Finally, and in marked contrast to our positive results with guinea pig serum, all attempts to produce a positive skin reaction to egg white by repeated intracutaneous doses, have so far failed. Presumably this failure depends upon the diet.

The Parenteral Administration of Sodium Ferrocyanide in Anemia. By James M. Bethea (by invitation) and Paul ReznikofF, New York, N. Y.

Oral administration of iron in iron deficient anemia may be unsatisfactory because of inadequate absorption, intolerance or, perhaps, the necessity for rapid response. Such conditions, although uncommon, make parenteral administration desirable.

Organic iron, although non-toxic, is expensive. Inorganic preparations in which iron is in the cation are locally toxic, precipitating proteins. We have used a ten per cent solution of sodium ferrocyanide in which iron is in the anion. This does not precipitate proteins in vitro and is non-toxic locally or generally when given parenterally. The icteric index in patients during administration showed no change and daily urinalyses showed albumin and red blood cells in only a small percentage of patients. The drug was administered parenterally ( 25 to $30 \mathrm{mgm}$. of iron daily) to 12 patients with iron deficient anemia and to 13 rabbits (10 to $20 \mathrm{mgm}$. of iron daily) with anemia caused by bleeding or by a milk diet. In the patients some reticulocyte response and subsequent rise in hemoglobin in uncomplicated cases occurred. In anemic rabbits marked response occurred. The ferrocyanide is, however, excreted up to 90 per cent in the urine of patients. In rabbits much less is excreted if the animal is markedly anemic.

The Effects of Repeated Injections of Histamine on Gastric Secretion. By Leon Schiff, Cincinnati, Ohio.

Over 400 subcutaneous injections of histamine have been given to one individual during a period of over two years. Continuous aspirations of the gastric juice have been made under the same conditions on over 200 occasions for periods of $2 \frac{1}{2}$ hours. An increase in the volume of gastric secretion with no increase in the total output of acid has been observed following single injections of histamine. A permanent increase in the volume of gastric juice obtained under fasting conditions without histamine has also been noted. In following the patient's general condition, with particular reference to the gastrointestinal tract and hematopoietic system, no harmful effects could be detected. The effects of atropine and pilocarpine have also been studied.

The Etiology of Whooping Cough. By Gerald S. Shibley, Cleveland, Ohio.

The Bordet-Gengou bacillus is considered by many to be the specific causative agent of whooping cough. Others believe that there is a virus component. In an effort to settle this question, freshly isolated $H$. pertussis was maintained in the so-called infective phase (" $S$ ") for 8 months; then, being theoretically virus free, was used to inoculate a chimpanzee. Whooping cough appeared after a 10 day incubation period. It was typical clinically, hematologically, bacteriologically, and at postmortem, pathologically (except for absence of 
organisms in ciliary apparatus). The laboratory phase, (" $R$ ”), presumably avirulent had failed previously to produce the disease in another chimpanzee. In spite of rigorous precautions two other chimpanzees in the adjoining room contracted coughs which lasted 6 weeks and were very suggestive of pertussis. The animals were not tame enough for successful cultural study. Subsequent attempts to produce whooping cough in these animals by the method described above failed, as would be expected if they had had the disease. The presence of immunity in the animals has been confirmed by their failure to contract the disease when inoculated with $H$. pertussis contained in pooled sputa from human cases.

\section{Physiological Relationships of Common Clinical Data in the Diagnosis of Myo-} cardial Disease. By IsaAc Starr, Jr., Philadelphia, Pa.

The application of cardiac output methods to patients requires so much apparatus and technique that there is little likelihood that they will become an aid in routine diagnosis. However, increased knowledge of cardiac physiology in disease, gained by means of cardiac output methods, may be expected to aid the diagnosis of cardiac disease by permitting more correct interpretation of the ordinary clinical data.

As a result of estimations of cardiac output on 250 patients (Starr, Donal, Margolies, Shaw, Collins and Gamble (in press)), relationships have been demonstrated to exist between cardiac work and heart volume, cardiac output and metabolism, cardiac output and body weight, etc. These relationships have been expressed mathematically and the resulting formulae combined so that the factor "cardiac output" is eliminated. As a result we have obtained a number of formulae which express normal physiological relationships and may be used for the detection of abnormal myocardial function without the necessity of estimating cardiac output. These formulae have been applied to the data of normal persons, and the normal limits determined. The great majority of patients with undoubted myocardial disease give results far outside the normal limits.

Examples of such formulae, expressed in the ordinary clinical units, follow. (1) $\frac{\text { Mean blood pressure }}{\text { Pulse rate }}\left(\begin{array}{c}78+1.2 \text { oxygen consumption) } \\ \text { ette area })^{3 / 2}=\mathrm{K},\end{array}\right.$

$$
\frac{\text { Mean blood pressure }}{\text { Pulse rate }}\left(\begin{array}{c}
45+0.9 \text { weight } \\
\text { area })^{3 / 2}=\mathrm{K} .
\end{array}\right.
$$

The lower normal limits are approximately $\mathrm{K}=-50$ and $\mathrm{K}=-100$ re. spectively; (2) may not be used in hyperthyroidism or hypertension. Neither gives evidence of coronary disease.

Relationships Derived from Measuring Solutes in Blood or Serum on a Water Basis. By F. William Sunderman and (by invitation) EnNion WilLIAMs, Philadelphia, $\mathrm{Pa}$.

With respect to solutions containing a high concentration of solids, as for example blood or serum, the distinction between concentration of solute per unit amount of solution and per unit amount of solvent becomes important. The concentration of solute per volume of solution is the relationship usually employed in clinical studies. It is, however, the concentration of solute per unit amount of solvent which has especial physicochemical significance and is related to osmotic equilibrium and to the activity of the solute. 
Relationships of significance which we have derived from the measurement of solutes of serum and cells on a water basis are the following:

(1) Following the ingestion of glucose by diabetic patients, the increase in the molal concentration of glucose is shown to be largely compensated for osmotically by the decrease in the molal concentration of chloride in the serum.

(2) By the measurement of solutes in serum on both a water and volume basis, it can be shown that the rise of glucose in the serum of diabetic patients tends to draw not only water but saline from the tissues. The water added to the serum dilutes the serum electrolytes and causes an inflow of total base and chloride from the tissues.

(3) We confirm MacKay's demonstration that there is equal distribution of sugar between the water of the corpuscles and the water of the serum although not an equal distribution between the serum and corpuscles on a volume basis.

(4) A linear correlation is demonstrated between the specific gravity and the water content of serum. This permits us to employ the relatively simple and dependable measurement of the specific gravity of serum without the additional measurement of its dry weight in order to calculate the concentration of a solute per unit amount of water in the serum with accuracy sufficient for many purposes.

\section{The Flow of Lymph as a Measure of Filtration from the Capillaries in Nor-} mal and Edematous Dogs. By A. A. WeECH and (by invitation), E. GoEtTSCH, New York, N. Y.

The study deals with a comparison of the relative rates of the filtration of fluid across the capillaries in normal dogs and in dogs exhibiting edema due to depleted plasma proteins. Data concerning capillary filtration were obtained by observing rates of lymph flow. When a cannula is first introduced into one of the main lymphatic trunks of the ankle and the flow of lymph stimulated by allowing the animal to walk about, the rate of flow is at first rapid but as collection is continued it becomes slower and finally remains relatively constant over long periods of time. The rapid initial rate probably results from the withdrawal of fluid which had previously accumulated in the interstitial spaces. The subsequent constant rates must correspond to the production of fresh lymph, that is, to the rate of filtration from the capillaries. Inasmuch as the number and diameter of lymphatic vessels in the region of the ankle is not subject to wide anatomical variation, ${ }^{1}$ the average lymph flow in a group of animals should be roughly proportional to capillary filtration in the region distal to the cannula, i.e., the foot. Among 13 normal dogs, studied in this manner, the constant rates of lymph flow varied between $0.05 \mathrm{cc}$. and $1.96 \mathrm{cc}$. per half hour and averaged $1.13 \mathrm{cc}$. per half hour. Among 8 edematous dogs the analogous rates varied from $0.01 \mathrm{cc}$. to $4.10 \mathrm{cc}$. per half hour and averaged $1.24 \mathrm{cc}$. per half hour. In one case only was the rate of flow greater than that included in the range for normal animals. In the normal group analyses of serum revealed an average total protein concentration of 5.70 grams per cent, of which 3.33 grams were albumin and 2.37 grams were globulin. The average colloid osmotic pressure of the serum calculated by the formula of Wells, Youmans, and Miller ${ }^{2}$ was $23.5 \mathrm{~cm}$. of water. In the edematous group the average serum

1 According to White, Field, and Drinker (Am. J. Physiol., 1933, 103, 34) there are "three or at the very most four" lymphatic vessels of approximately equal size in this region.

2 Wells, H. S., Youmans, J. B., and Miller, D. G., Jr., J. Clin. Invest., 1933, 12, 1103. 
protein concentration was 4.60 grams per cent, the partition being 1.43 gram of albumin and 3.17 grams of globulin. The calculated osmotic pressure was $13.8 \mathrm{~cm}$. of water. A reduction in serum osmotic pressure of this magnitude would be expected to produce an increase in filtration pressure and a significant rise in the rate of fluid filtration across the capillaries. The failure to observe a significant rise is not interpreted as evidence against the importance of a balance between colloid osmotic pressure of plasma and capillary blood pressure in determining normal fluid distribution. It does, however, suggest the existence of compensatory changes at the wall of the capillary in association with low plasma osmotic pressure, the nature of which is yet obscure. The findings also suggest that failure of the mechanism for reabsorption of fluid into the capillaries may be of greater importance in the pathogenesis of edema than an increase in the rate of capillary filtration.

The Rôle of Pressor Substances in Arterial Hypertension. By R. B. CApps, E. B. Ferris, F. H. L. TAYlor (by invitation), and Soma Weiss, Boston, Mass.

Recently it has again been suggested that circulating hormones or other chemical substances are responsible for certain types of hypertension. The problem of a "pressor" substance appearing in the blood and urine of normal and hypertensive subjects has, therefore, been investigated.

Twenty-four-hour amounts of urine from normal subjects and from patients with essential, malignant, and nephritic hypertension have been extracted according to the method of Bohn. These extracts were injected intravenously into anesthetized cats, and femoral blood pressures recorded graphically. About 50 test animals were used. Particular attention was paid to testing the same extract on different animals under the same and varied anesthetics, as well as to testing different extracts from the same patient. Both the acetone and alcohol fractions were studied.

A definite pressor effect was obtained from the urine of a majority of the patients tested, but this effect occurred as frequently in normals as in hypertensives, and no significant difference was noted quantitatively. The separation of the depressor from the pressor effect by acetone-alcohol fractionation has not proved feasible. Upon injection of the urine extract, there frequently was an initial depression followed by an elevation of the blood pressure from a few millimeters to as high as $90 \mathrm{~mm}$. $\mathrm{Hg}$. The type of blood pressure curve obtained was extremely variable, and depended in part upon: (1) unknown variables in individuals from day to day; (2) variations as yet unexplained in the response of different cats and also of the same cat to the same extract; (3) the rate of injection of the extract; (4) the type and amount of anesthetic used. There was no correlation between the type of curve and the initial blood pressure level or between the type of curve and the animal's response to either fluids, adrenalin or "carotid sinus reflex."

No significant pressor effect was obtained with blood extracts from either normal subjects or patients with essential or malignant hypertension.

Our results do not bear out the contention of certain investigators that there is a relationship between hypertension and the presence of increased amounts of pressor materials in the blood and urine.

Further studies regarding the exact nature of the pressor material usually found in urine are in progress. 
A Histological Study of the Arterioles of the Muscle and Skin from the Arm and Leg in Individuals with Coarctation of the Aorta. By Ashton Graybiel and Arthur W. Allen (by invitation) and Paul D. White, Boston, Mass.

Resolution of Experimental Tuberculous Pneumonia. By Henry S. Willis, Northville, Mich.

The Metabolism of Creatine in Muscle Disease. By A. T. MILHORAT (by invitation) and H. G. WoLfF, New York, N. Y.

Patients with diseases which affect the muscular system commonly have. a creatinuria even when they are maintained on a creatine-free diet.

In some conditions, notably amyotonia congenita, progressive muscular dystrophy and myasthenia gravis, considerable amounts of creatine are excreted even when the reduction in muscle mass appears to be slight. Accompanying the creatinuria there is usually a diminished ability to retain ingested creatine (low creatine tolerance) and frequently a decreased excretion of creatinine. Moreover, the administration of glycocoll is followed by an increase in the amount of urinary creatine. Ingestion of creatine after several days of glycocoll administration exaggerates the deficit, that is, creatine is even more fully excreted. This is particularly true in myasthenia gravis where the spontaneous creatinuria is often very slight or even absent for short periods.

The amount of creatine excreted is not a direct index of the amount of muscle wasting. In conditions such as progressive muscular atrophy, amyotrophic lateral sclerosis, myotonia atrophica and peripheral neuritis, extensive muscle wasting may occur with only a slight creatinuria. Most cases in this group exhibit little change in their metabolism of creatine as indicated by the creatine tolerance test and the effect of glycocoll. However, in rare instances of myotonia atrophica and extensive muscular wasting after anterior horn cell disease, defects in the metabolism of creatine under the above test conditions were observed.

Thus patients with muscle disease may be grouped on the basis of their metabolism of creatine: (1) Those in whom usually the creatinuria is greater and the creatine tolerance grossly deficient. This deficiency is always exaggerated by the administration of glycocoll. (2) Those in whom the creatinuria is small and the creatine tolerance but slightly deficient, and not exaggerated by the administration of glycocoll. Such patients may have advanced atrophy in certain important muscle groups. Creatine output and tolerance would therefore appear to be an expression of the total mass of improperly functioning muscle, and not, per se, an index of the amount of atrophied muscle or of the primary site of disease.

These tests, based on the metabolism of creatine, are of value in the differential diagnosis of muscle disease.

Congenital Heart Block. Report of the Third Case of Complete Heart Block Studied by Serial Sections Through the Conduction System. By WaLLACE M. Yater, Washington, D. C., and (by invitation) Wrlliam G. Leaman, Philadelphia, Pa., and Virgil Heath Cornell, Washington, D. C.

At the last annual meeting of the Society a report was made by Yater, Lyon and $\mathrm{McNabb}$ of the second case of complete heart block of congenital origin studied by serial sections through the conduction system; the first case had pre- 
viously been reported by Yater. These two cases constituted the only cases ever studied in this way. Only six cases of congenital heart block including the present one, have been studied by necropsy. In all six, congenital defects in the septum between the right and left sides of the heart were present. The present case is that of a child who lived 18 hours, during which time he was intensely cyanotic. Numerous electrocardiograms were taken, all showing complete heart block, and the effect of atropine was studied. An x-ray film of the chest was also taken. Examination of the heart showed practically complete absence of the interauricular septum and of most of the membranous portion of the interventricular septum. Serial sections showed that there was practically complete separation of the auricles and ventricles by the central fibrous body in the region where the specialized muscle bundle normally bridges the auriculoventricular fibrous junction. The bundle of His was well formed but was disconnected from the auriculoventricular node in this region. Lantern slides are shown of the electrocardiograms, roentgenogram, macroscopic appearance of the heart and of illustrative microscopic sections.

The Relationship of the Intrinsic Factor to a Hematopoietic Material in Concentrated Human Gastric Juice. By O. M. Helmer and PAUL J. Fouts (by invitation), and L. G. ZERFAS, Indianapolis, Indiana.

The demonstration of a substance in normal human gastric juice capable of inducing a reticulocytosis when injected intramuscularly into patients with Addisonian pernicious anemia during blood relapse, has been found to be dependent upon the process of concentration of the gastric juice by vacuum distillation and upon the presence of both the intrinsic factor and an extrinsic factor or factors. As the intrinsic factor was destroyed or altered during the process of formation of the hematopoietic substance, the substance formed is not identical with the intrinsic factor. 